\title{
Pharmacological Treatment of Alzheimer's Disease: Is it Progressing Adequately?
}

\author{
Alfredo Robles*
}

La Rosaleda Hospital, Santiago León de Caracas street, no. 1, 15706 - Santiago de Compostela, Spain

\begin{abstract}
Introduction: Between 1993 and 2000 four acetylcholinesterase inhibitors were marketed as a symptomatic treatment for Alzheimer's disease (AD), as well as memantine in 2003. Current research is focused on finding drugs that favorably modify the course of the disease. However, their entrance into the market does not seem to be imminent.

Research Development: The aim of AD research is to find substances that inhibit certain elements of the AD pathogenic chain (beta- and gamma-secretase inhibitors, alpha-secretase stimulants, beta-amyloid aggregability reducers or disaggregation and elimination inductors, as well as tau-hyperphosphorylation, glutamate excitotoxicity, oxidative stress and mitochondrial damage reducers, among other action mechanisms). Demonstrating a disease's retarding effect demands longer trials than those necessary to ascertain symptomatic improvement. Besides, a high number of patients (thousands of them) is necessary, all of which turns out to be difficult and costly. Furthermore, it would be necessary to count on diagnosis and progression markers in the disease's pre-clinical stage, markers for specific phenotypes, as well as high-selectivity molecules acting only where necessary. In order to compensate these difficulties, drugs acting on several defects of the pathogenic chain or showing both symptomatic and neuroprotective action simultaneously are being researched.

Conclusions: There are multiple molecules used in research to modify AD progression. Although it turns out to be difficult to obtain drugs with sufficient efficacy so that their marketing is approved, if they were achieved they would lead to a reduction of $\mathrm{AD}$ prevalence.
\end{abstract}

Keywords: Acetylcholinesterase inhibitors, Alzheimer's disease, antioxidants, cell therapy, disease-modifying drugs, immunotherapy, memantine, secretase inhibitors.

\section{INTRODUCTION}

From 1906, when the first case of Alzheimer's disease (AD) was described, until 1993, when tacrine was marketed, there were no specific treatments for this disorder. Between 1996 and 2000, new anticholinesterases entered the market and so did memantine in 2003. Currently, the marketing of new formulas for symptomatic treatment does not seem to be imminent and the interest of research is focused on finding products aimed at modifying the course of the disease. Unfortunately, years and years are going by and these drugs do not reach the market. This paper analyses synoptically the state of affairs of this research and the reasons hindering such an expected step in the history of AD.

\section{SYMPTOMATIC TREATMENT}

Since the 70s it is known that brain cholinergic deficiency is noticeable and early in $\mathrm{AD}$, taking part in the genesis of certain manifestations such as hypomnesia. Tacrine (the first AD symptomatic treatment) is an acetylcholinesterase inhibitor (ACEI) which boosts brain cholinergic activity. It requires four doses a day and some patients do not have enough enzymatic resources in their liver to detoxify the products of its metabolism. New prescriptions of tacrine were interrupted when donepezil was approved in 1996,

*Address correspondence to this author at the La Rosaleda Hospital, Santiago León de Caracas street, no. 1, 15706 - Santiago de Compostela, Spain; Tel: +34 981551200 (ext. 1003);

E-mail: alfredorobles@hospitalrosaleda.com since the latter is well-tolerated and suitable for a daily dose. Subsequently, rivastigmine (1998) and galantamine (2000) were approved, two anticholinesterases which inhibit acetylcholinesterase to a lower extent than donepezil does. Rivastigmine compensates it through the simultaneous inhibition of butyrylcholinesterase and galantamine by exerting allosteric modulation of presynaptic muscarinic receptors, thus increasing acetylcholine secretion at the synaptic space. In clinical trials with ACEI against placebo, significant improvement was observed in cognition, behavior, functional autonomy and clinical global impression in patients ranging from incipient to moderately advanced AD [1]. A metaanalysis of 10 trials shows that, from 6 months onwards, patients treated with placebo worsen an average of 2.16 points on the cognitive scale ADASCog (70 points), while those treated with an ACEI in optimum doses undergo an average improvement of 0.27 points (average difference $=$ 2.43 points) [1]. The difference among ACEIs' effect does not exceed one point and thus meta-analyses do not find any significant difference regarding effectiveness on cognition among the three ACEI in use [1-3].

There exists a constant excess of glutamate in the synaptic clefts in diseased cells, which determines an excessive entrance of $\mathrm{Ca}^{++}$into the cell through the existing channels in glutamate NMDA receptors. That's why the post-synaptic cell is permanently depolarized, thus not being functional. Memantine, a NMDA receptor antagonist, prevents such continuous depolarization and keeps the usefulness of postsynaptic cells. Due to its voltage-dependent action mecha- 
Table 1. Drugs with Symptomatic and Neuroprotective Action

\begin{tabular}{|l|l|}
\hline & Action \\
\hline \hline Dimebolin & ACEI + inhibitor of calcium L-channels and NMDA receptors \\
\hline Huperzine A & ACEI + antioxidant and stimulant of muscarinic and nerve growth factor receptors \\
\hline Phenserine & ACEI + sAPP- $\beta$ and $\beta$ A reducer \\
\hline Memoquin & ACEI + I-BACE, antioxidant and $\tau$-hyperphosphorylation reducer \\
\hline Bis-tacrine & tacrine dimmer. ACEI + I-BACE-1 and anti-NMDA \\
\hline Lipocrine & tacrine (ACEI) and lipoic acid (antioxidant) hybrid \\
\hline Tacrine-melatonin hybrids & ACEI + antioxidants \\
\hline Ladostigil & rivastigmine (ACEI) and rasagiline (antioxidant) hybrid \\
\hline Memantine & anti-NMDA + PP-2A stimulant (it decreases neurofibrillary degeneration), oxidative stress and activated microglia reducer \\
\hline
\end{tabular}

sAPP- $\beta$ : $\beta$ variant of the soluble APP.

nism, low-moderate affinity towards NMDA receptors and a fast channel-blocking/unblocking kinetics, when a stimulus from the pre-synaptic cell arrives, it allows the opening of the $\mathrm{Ca}^{++}$channels and a normal action potential takes place in the post-synaptic neuron [4]. Thus, a population of neurons which had already lost their activity is able to prolong it due to the action of memantine. This explains its positive effect on cognition and functional autonomy [5, 6] as well as on behavior [7-9], allowing it to be marketed in 2003 for the treatment of patients in moderately advanced and advanced stages (with scores in the Folstein mini-mental state examination -MMSE - below 15). A meta-analysis of studies including patients with less advanced AD developed in 2007 allowed to extend its use to moderate AD (MMSE scores ranging between 15 and 19) [5, 10].

Although ACEI are more effective during initial stages of dementia and memantine in its advanced stages, both treatments are effective throughout the whole evolution of the Alzheimer's disease. In fact, the US Food and Drug Administration (FDA) approved in 2007 the use of donepezil in ad- vanced $\mathrm{AD}$ and, when experimentation with memantine in incipient $\mathrm{AD}$ prolongs, the positive effect obtained in the trials carried out so far could be verified [6, 11-13].

\section{ADVANCES IN SYMPTOMATIC TREATMENT}

Immediate marketing of new symptomatic treatments for AD does not seem foreseeable. However, the use of the ACEI available might be extended to the advanced stages of the disorder, following the path of donepezil. The appearance of new formats in 2007 and 2008 (galantamine in sustained-release capsules, donepezil in flas and rivastigmine patches) has increased the treatment's tolerability, comfort and compliance. Memantine shows high tolerability and effectiveness in daily dose $[14,15]$, so that such a dosage has been accepted since 2008 .

Some of the drugs researched to modify the course of AD have symptomatic effects (Table 1). If any of them were used as a progression modifier, it would also increase at the same time the arsenal of symptomatic treatments. It may also

Table 2. Genes in which Determining Mutations and Susceptibility Polymorphisms (Associated to a Higher or Lower Risk) Related to AD have been Found

\begin{tabular}{|c|c|c|c|c|c|}
\hline Gene & Protein & Chromosome & \multicolumn{3}{|c|}{ Known FAD Pathogenic Mutations* } \\
\hline PSEN1 & presenilin 1 & 14 & \multicolumn{3}{|c|}{173} \\
\hline & & & $\mathrm{SA}^{* *}$ & $\mathrm{OR}^{\mathrm{a}}$ & $\mathrm{OR}^{1}$ \\
\hline$A P O E$ & apolipoprotein E & 19 & $\varepsilon 4$ vs $\varepsilon 3$ & 3.68 & 3.81 \\
\hline CHRNB2 & $\beta 2$ subunit of the neuronal nicotinic receptor & 1 & T vs $\mathrm{G}$ & 0.67 & 0.69 \\
\hline $\mathrm{CH} 25 \mathrm{H}$ & cholesterol 25-hydroxylase & 10 & T vs $\mathrm{C}$ & 1.44 & 1.38 \\
\hline SORL1 & Sortilin-related receptor & 11 & G vs C & 0.9 & 0.7 \\
\hline CALHM1 & calcium homeostasis modulator 1 & 10 & T vs C & 1.42 & 1.42 \\
\hline CST3 & cystatin $\mathrm{C}$ & 20 & C vs G & 1.23 & 1.28 \\
\hline$A C E$ & angiotensin I converting enzyme 1 & 17 & C vs T & 0.83 & 0.79 \\
\hline
\end{tabular}

*: Taken from http://www.molgen.ua.ac.be/ADMutations/ in November 2008.

**: Among the numerous genes in which susceptibility polymorphisms to develop sporadic AD have been found, we have pointed out those 10 genes which, up to now, have shown a greater degree of association (taken from http://www.alzforum.org/res/com/gen/alzgene/ in November 2008).

FAD: familial Alzheimer's disease. $\mathrm{OR}^{\mathrm{a}}, \mathrm{OR}^{\mathrm{b}}$ : Odds ratio obtained from the meta-analysis of all available studies (a) and studies on Caucasians (b). SA: susceptibility alleles. 
Table 3. Some of the Pathological Events that Take Place in AD

\begin{tabular}{|ll|}
\hline$\bullet$ & Abnormal hydrolysis of APP $(\beta$-secretase and $\gamma$-secretase $) \rightarrow \beta$ A production $\left(\beta \mathrm{A}_{40}, \beta \mathrm{A}_{42}\right)$ \\
\hline$\bullet$ & Fibrillogenesis: polymerization and formation of $\beta$ A oligomers \\
\hline$\bullet$ & Aggregation $\rightarrow$ final formation of neuritic plaques \\
\hline$\bullet$ & Neurofibrillary degeneration: hyperphosphorylation of $\tau$-protein $\rightarrow$ neurofibrillary tangles \\
\hline$\bullet$ & Glutamate excess in synapses $\rightarrow$ excitotoxicity \\
\hline$\bullet$ & Activation of microglia and presence of inflammatory proteins \\
\hline$\bullet$ & Imbalance in intracellular ion homeostasis (calcium, copper, iron, zinc) \\
\hline$\bullet$ & Oxidative stress $\rightarrow$ free radicals toxicity \\
\hline$\bullet$ & Alterations of the mitochondrial membrane $\rightarrow$ failure of the cellular energetic system \\
\hline
\end{tabular}

be that the symptomatic effect achieved will be precisely that which would allow them to enter the market.

\section{TREATMENTS THAT MODIFY THE EVOLUTION OF THE DISEASE}

The knowledge of the etiopathogeny of AD is gradually increasing. A large number of mutations that lead to the development of familial $\mathrm{AD}$, and numerous susceptibility polymorphisms that increase the risk of suffering sporadic AD, have already been identified (Table 2). An early and essential phenomenon is the formation of beta-amyloid $(\beta \mathrm{A})$ and its aggregation, followed by a sequence of pathological events that lead to cell dysfunction and, subsequently, to premature cell death (Table 3). Certain susceptible brain regions are affected first, and the topographical expansion follows a regular chronology in typical cases $[16,17]$. Researchers try to intervene in the steps of this pathogenic chain in order to slow down its morbid process. However, it is known that the administration of a neuroprotective drug does not necessarily involve any modification in the evolution of the disease and, when such a modification is achieved, it frequently does not take place to a significant degree.

The symptomatic treatment acts by reducing a neurochemical imbalance which gives rise to particular symptoms (Fig. 1). When the treatment is withdrawn, its beneficial effect disappears (Fig. 2.4). When a drug improves the condition of AD patients, it is sometimes doubtful if the improvement is due to a symptomatic action or to a modification in the course of the disease, or if both effects act together [18]. There are some aspects of the evolution that are useful in checking if the course of the disease is changing [18-21]:

a) If a drug extends the time that elapses until a developmental moment is reached (a further stage of dementia, the need to be institutionalized, death, etc.), we may attribute evolution-modifying properties to it, once we have excluded the intervention of any other influent factor.

b) A slower progression than expected also suggests that the drug is not merely symptomatic. In an evolutionary diagram, a progressively wider difference between the functional capacity of medicated and unmedicated patients would be observed (diverging lines) (Fig. 3.4 and 3.5). If progression speed is deducted from the slope of the evolution line, it is then necessary to compare the evolution of patients in equivalent clinical stages.

c) When a solely symptomatic drug is stopped, the evolution curve will quickly overlap that of the untreated patients (Fig. 2.4). The improvement (or less impairment) achieved by an evolution-modifier drug does not disappear, or it does only partially, after being stopped (Fig. 2.5).

d) Patients receiving a symptomatic treatment, once the necessary time to reach its maximum effect has gone by, should be comparable to other patients who are in the same stage of the disease and began the same treatment before. If the former are in a worse situation than the latter, it should then be inferred that the treatment modifies the course of the disease and, for such a reason, its early onset has long-lasting accumulative effects (Fig. 4).

e) Paraclinical parameters acting as progression markers should show progression slowness in patients receiving drugs which modify the course of the disease. Magnetic resonance image of the hippocampal region, positron emission tomography (PET) with markers of amyloid plaques, or modifications of $\beta \mathrm{A}_{42}$ and tau or phospho-tau in cerebrospinal fluid are some useful elements for this purpose, although their validity has not been fully proven yet [20, 22]. Tests based on cerebral metabolism or perfusion (FDG-PET or HMPAO-SPECT, for instance) do not have the same validity, since some symptomatic treatments can modify them [18].

\section{Neuroprotective Action of Drugs Approved for the Symptomatic Treatment of AD}

Several evidences point out that ACEI and memantine have a modifying effect on the evolution of AD. O. Lopez et $a l$. have observed a higher interval until the patients administered ACEI are admitted to a nursing home [23] and, if memantine is added, such an interval is significantly higher and, moreover, survival time is also extended (paper by OL Lopez et al. read at the $60^{\text {th }}$ Annual Meeting of the American Academy of Neurology, April 2008).

- Donepezil acts on the deep region of the acetylcholinesterase, where the acetylcholine is hydrolyzed, and on the surface area that interacts with $\beta \mathrm{A}$ and facilitates its aggregation. Its double nature gives it, 


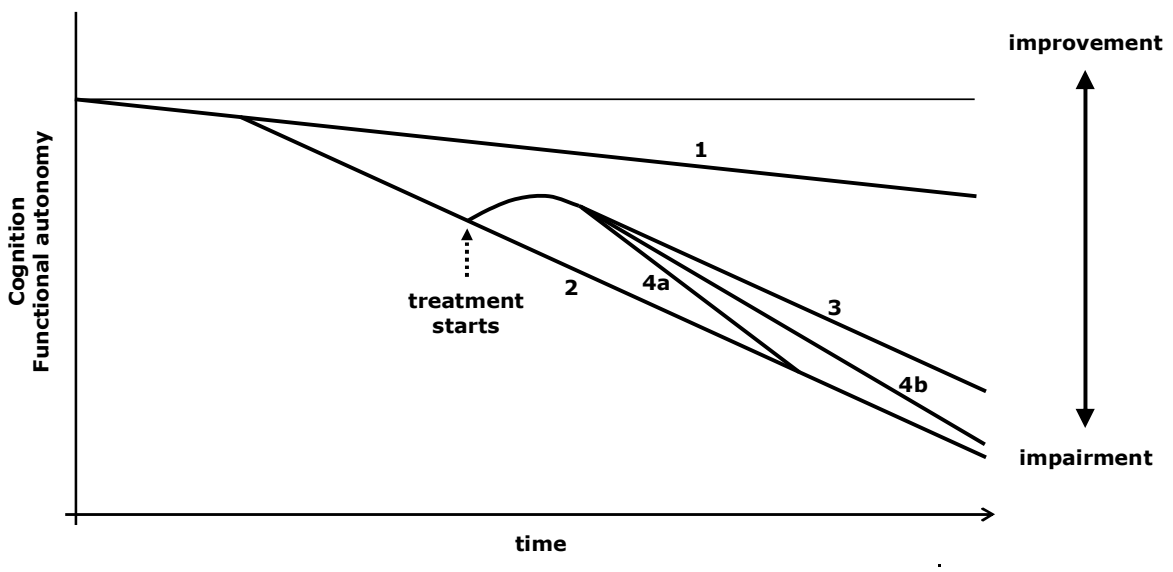

Fig. (1). Virtual graph $\left(^{*}\right)$ of the possible effects of a symptomatic treatment. *: In reality, the natural evolution of impairment is not lineal and varies according to the stage of the disease; however, the lineal diagram facilitates the conceptual understanding of the action of the drugs. 1: Cognitive decline related to ageing. 2: Cognitive and functional loss due to an untreated progressive disease. 3: The optimum effect of a solely symptomatic treatment is maintained throughout. 4: Symptomatic treatment may produce a transitory beneficial action (4a) or a long-lasting benefit but to a progressively lower degree (4b).

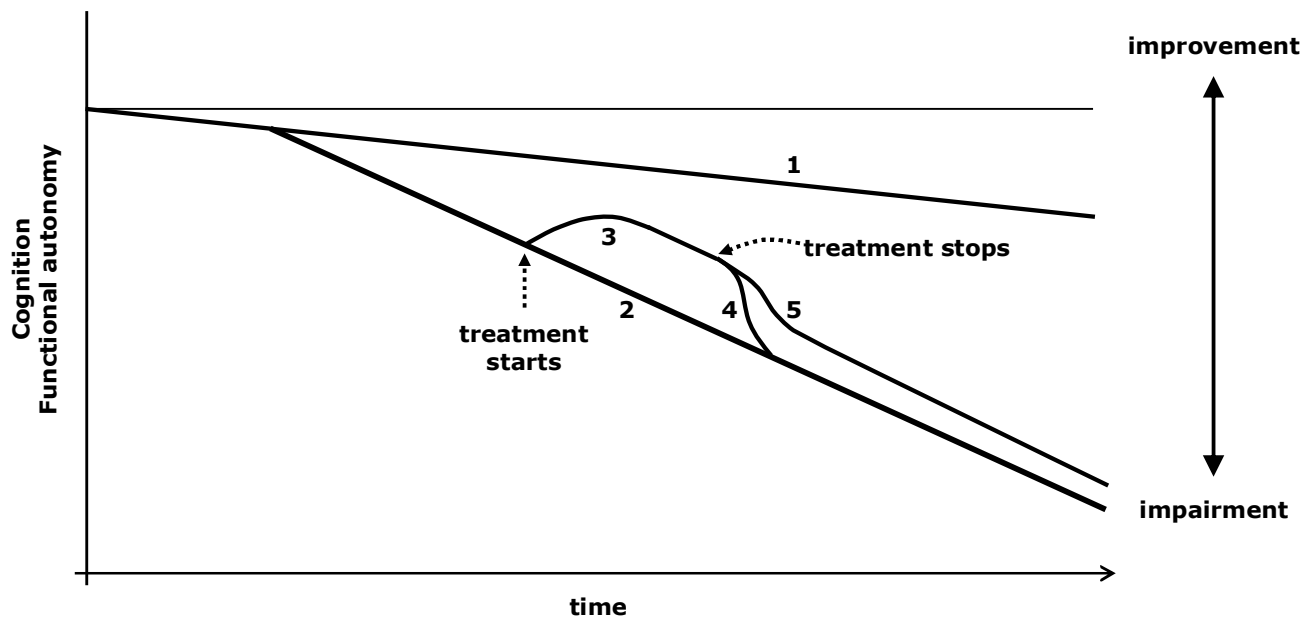

Fig. (2). Virtual graph $(*)$ of the possible effects of suspending a treatment with symptomatic effect. *: In reality, the natural evolution of impairment is not lineal and varies according to the stage of the disease; however, the lineal diagram facilitates the conceptual understanding of the action of the drugs.

1: Cognitive decline related to ageing. 2: Cognitive and functional loss due to an untreated progressive disease. 3: Improvement produced by treatment. 4: If a treatment is only symptomatic, its action is lost when it is suspended and the patient follows the evolution of untreated patients. 5: If the treatment, apart from being symptomatic, also modifies the course of the disease, its symptomatic action is lost when it is suspended, but the modification already achieved is held and the patient follows a progression line that does not overlap that of untreated patients.

apart from its symptomatic effect, a protective action against $\beta$ A toxicity [24]. Other effects of donepezil, such as the stimulation of $\alpha-7$ nicotinic receptors (which induces overexpression of the antiapoptotic bcl-2 protein) $[25,26]$ or the activation of $\sigma-1$ receptors (which reduces lipid peroxidation in hippocampal regions) [27], contribute to its potential neuroprotection. These effects may explain that hippocampal atrophy is slower in patients treated with donepezil [28, 29]. In a 3-year follow-up of two groups of patients (some treated with donepezil the whole time and others only during the last two years), patients treated with the drug since the beginning of the project retained better cognitive function at the end of the 3year period (according to MMSE) [30]. The cumulative effect after a longer drug exposure represents a possible evolutionary modification (Fig. 4).
- The dual action of rivastigmine consists of inhibiting the hydrolysis of acetylcholine by acetylcholinesterase and butyrylcholinesterase. Since butyrylcholinesterase has greater impact on the formation of neuritic plaques than acetylcholinesterase [31], its inhibition may contribute to the lower cortical temporoparietal atrophy observed in patients treated with rivastigmine [32]. In a 5-year follow-up of patients treated with rivastigmine, MMSE scores show an increasing difference from the expected scores of untreated individuals [33] (model 5b in Fig. 3). The outcome should be interpreted cautiously due to the high number of patients lost during the follow-up period (basal sample: 1998, after 5 years: 83). In another study it was observed the evolution of patients who gave up the treatment prematurely, using three double-blind trials of rivastigmine against placebo; at the 


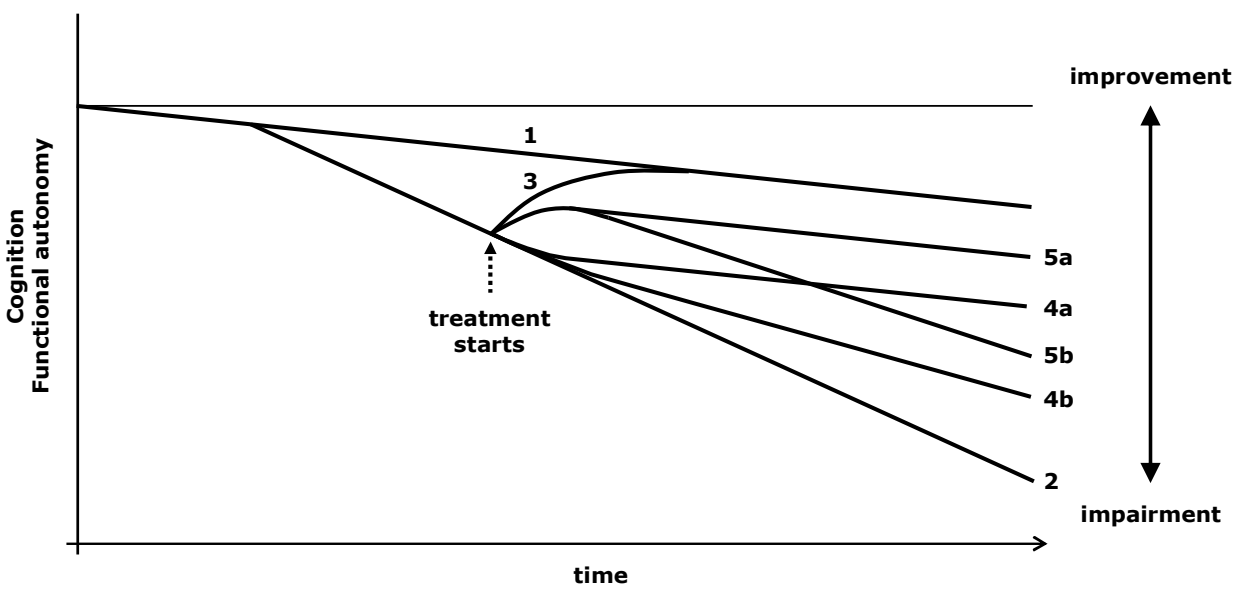

Fig. (3). Virtual graph $(*)$ of the possible effects of a treatment that modifies the evolution of the disease. *: In reality, the natural evolution of impairment is not lineal and varies according to the stage of the disease; however, the lineal diagram facilitates the conceptual understanding of the action of the drugs. 1: Cognitive decline related to ageing. 2: Cognitive and functional loss due to an untreated progressive disease. 3 : Effect of a curative treatment (reversible disease). 4: Action of a treatment that modifies impairment progression speed, either by recovering the physiological slope (optimum situation, 4a) or by reducing progression speed (4b). 5: A treatment may have both symptomatic and modifying effects on the evolution of the disease, so that, after achieving an initial symptomatic improvement, the patient shows a diverging progression line in comparison to that of untreated patients, regaining (5a) or not (5b) the physiological slope (1).

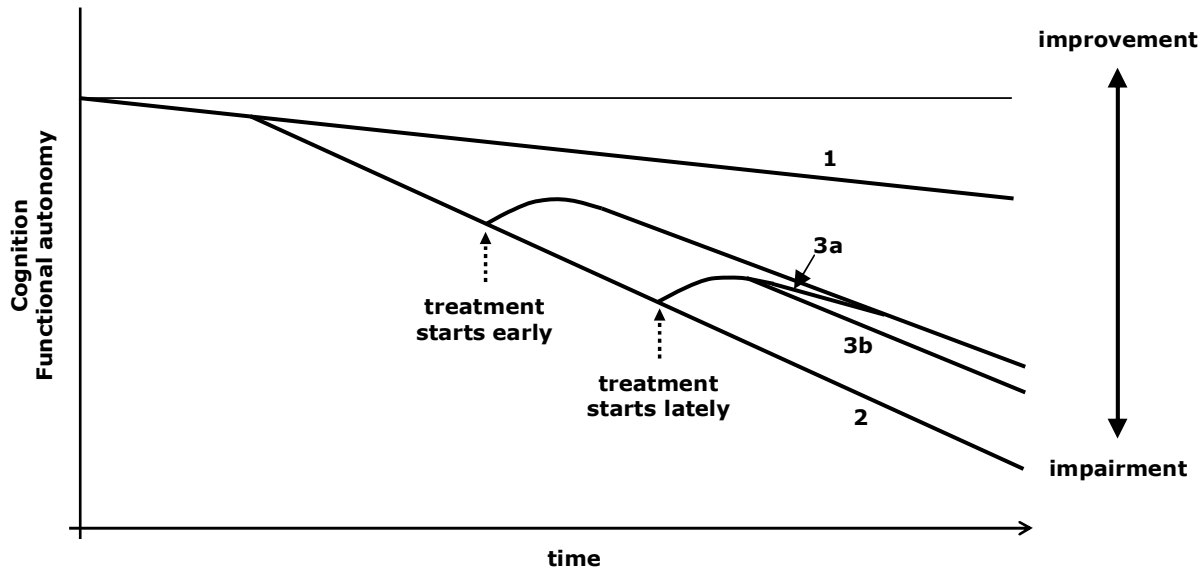

Fig. (4). Virtual graph (*) of the possible effects of a symptomatic treatment. *: In reality, the natural evolution of impairment is not lineal and varies according to the stage of the disease; however, the lineal diagram facilitates the conceptual understanding of the action of the drugs. 1: Cognitive decline related to ageing. 2: Cognitive and functional loss due to an untreated progressive disease. 3a: If a symptomatic treatment starts late, the improvement catches that of patients who began treatment earlier. $3 \mathrm{~b}$ : If the treatment also modifies the course of the disease, its late onset does not allow reaching the benefit obtained with an earlier onset.

end of the $26^{\text {th }}$ week, those patients who had taken rivastigmine in any previous period showed superior cognitive performance (ADAScog) than those of the placebo group [34]. This outcome, according to the graph in Fig. (2), points out that rivastigmine modifies the course of the disease.

- The stimulation of $\alpha-7$ nicotinic receptors by galantamine enhances the expression of the antiapoptotic bcl-2 protein and has protective effects against glutamate excitotoxicity, stimulated by $\beta \mathrm{A}[25,26,35$, 36]. In a 36-month follow-up of patients from two double-blind trials with galantamine against placebo of 6 and 3 months of duration, the scores on the cognitive scale ADAScog-11, which are always favorable to galantamine-treated patients, follow a diverging evolution in relation to the scores expected for untreated patients [37] (model 5b in Fig. 3).
- In many pathological states of the nervous system, $\mathrm{AD}$ among them, excitotoxicity contributes to functional and structural damage. In these situations, memantine experimentally shows a protective effect. This protective effect is reinforced by its ability to reduce the action of the activated microglia [38] and because it stimulates protein phosphatase $2 \mathrm{~A}$, thus reducing tau phosphorylation [39, 40]. After a 28-week double-blind trial of memantine against placebo, a 24week open study was carried out. Patients treated with the drug continued with medication and those receiving placebo changed to memantine. In the end, the patients treated since the $29^{\text {th }}$ week, in spite of having improved, did not reach the same beneficial situation regarding cognition and functional autonomy as those patients who had received memantine since the first day of the double-blind trial. The fact that no overlap took place between the curves may 
point out that memantine exerts a modifying effect on the evolution of AD [41] (see Fig. 4).

- $\quad$ Patients with probable AD treated with combination therapy (ACEI plus memantine) showed significantly lower mean annualized rates of deterioration in functional capacity when compared to patients who received ACEI alone or no treatment [42].

\section{Drugs Under Research for Modifying the Evolution of AD}

\section{II.A. Drugs to Reduce BA Production}

Insoluble $\beta A$ is formed because $\gamma$-secretases (presenilins) and $\beta$-secretases (BACE - $\beta$-site APP cleaving enzyme-) cut the transmembrane amyloid precursor protein (APP), releasing this intermediate fragment, instead of being done by $\gamma$ and $\alpha$ secretases, which release the soluble fragment APPs- $\alpha$ (Fig. 5). In the last few years, the strategy of inhibiting $\gamma$ - or $\beta$-secretase has given a hint of hope in the treatment of AD. Most of $\gamma$-secretase inhibitors also inhibit the action of this enzyme on the notch protein and other protein substrates that take part in cell differentiation processes and therefore are not well tolerated (they produce alterations in thymus, intestine and spleen in experimental mice) [43-45]. For this reason, allosteric modulators or selective inhibitors of the $\gamma$ secretase which acts on the APP are currently being synthesized [45-47]. The $\gamma$-secretase inhibitor LY450139 has already started a phase-III trial. In the phase-II trial a tendency towards cognitive improvement and lower $\beta \mathrm{A}_{40}$ levels in blood and cerebrospinal fluid took place against placebo; however, no significant differences were reached [47]. The inhibitor may also cause eosinophilia and diarrhea and, in one case, death occurred after a digestive hemorrhage due to Barrett's esophageal ulcer developed during the treatment [47]. Imatinib mesylate (antineoplastic) has shown an inhibiting action of $\gamma$-secretase without altering the notch sub- strate, so that its experimentation in AD has been suggested [48]. Several experts think that the action on $\beta$-secretase would be better tolerated, having tested $B A C E-1$ inhibitors (I-BACE1) [49] and antibodies against the BACE cleavage site of the APP [50]. The GSK188909 I-BACE1, for instance, reduces $\beta \mathrm{A}$ load in transgenic mice [51], and CTS21166 showed good tolerability and plasmatic reduction of $\beta \mathrm{A}$ in a phase I trial with healthy people. Successive generations of I-BACE have gradually obtained structures of low molecular weight and high inhibiting capacity for their possible use in clinical practice [52-60]. Apart from APP, BACE1 also hydrolyzes sialyltransferase ST6Gall (in the Golgi apparatus) and neuroregulin-1, which takes part in myelination processes occurring mainly after birth. Encouraging results have been obtained in BACE1 knockout mice, pointing out that the use of I-BACE in adults might not have negative repercussion $[61,62]$. It is foreseeable that broad clinical trials with human patients will be undertaken soon. Among the multifunctional molecules under research, we can mention Memoquin which, apart from being I-BACE1, has antioxidant properties, is an ACEI and reduces $\beta \mathrm{A}$ aggregation and tau-hyperphos-phorylation [63].

Instead of inhibiting $\beta$ - or $\gamma$-secretases, there is the possibility of stimulating the pathway of the $\alpha$-secretase. Retinoic acid, final product of the metabolic cascade of vitamin A, modulates biological processes of proliferation, differentiation and apoptosis, stimulates the activity of $\alpha$-secretase ADAM-10, protects from $\beta$ A toxicity and is reduced in AD $[64,65]$. Therefore, retinoic acid analogs such as fenretinide [65] or activators of its PAC1 receptor, such as the neuropeptide PACAP (pituitary adenylate cyclase-activating polypeptide) [66], constitute research elements to slow down the progression of AD. Among the multifunctional drugs which stimulate the non-amyloidogenic pathway of the $\alpha$ secretase, statins and ladostigil can be included and shall be commented on later.

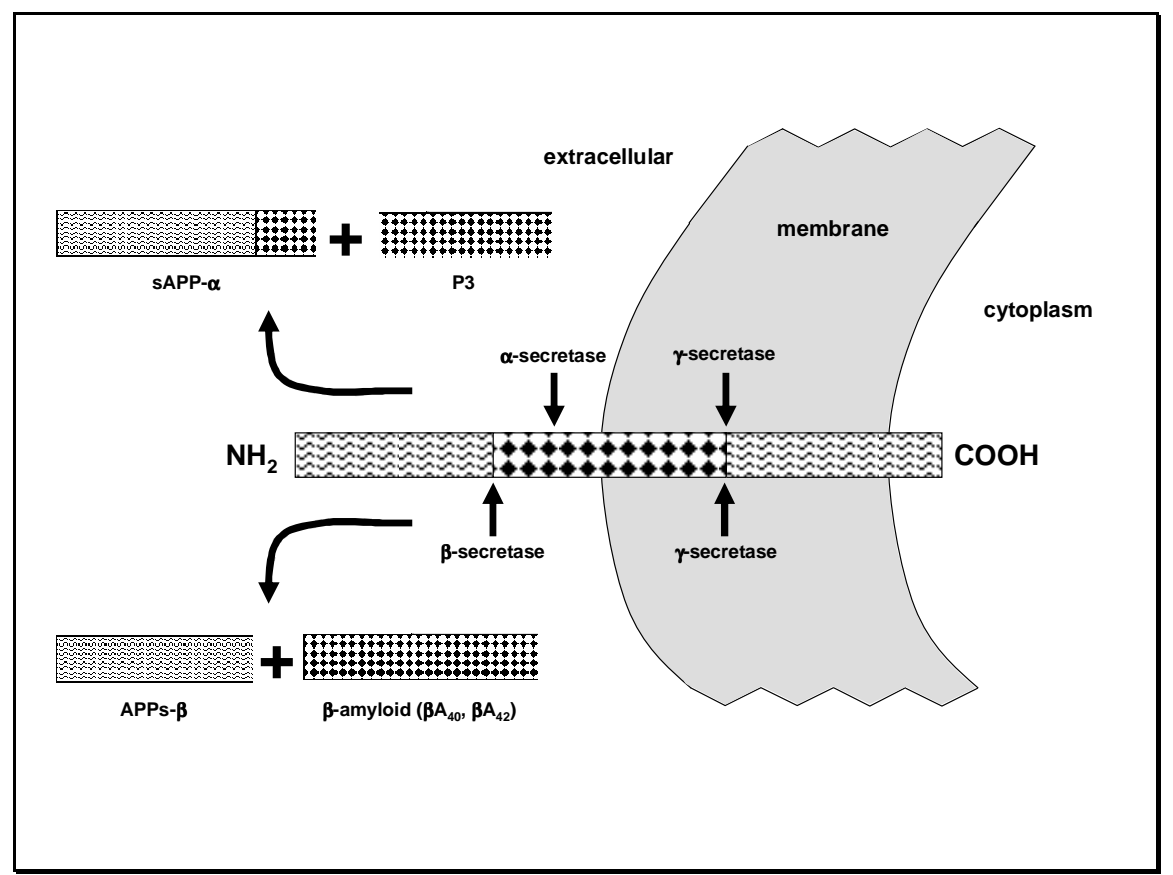

Fig. (5). Transmembrane amyloid precursor protein (APP). In normal conditions, $\alpha$ - and $\gamma$-secretase act on it, thus producing the non-toxic fragments sAPP- $\alpha$ and P3. In AD $\beta$ - and $\gamma$-secretase take part, releasing a less soluble fragment ( $\beta \mathrm{A})$ that is subsequently polymerized and forms insoluble deposits. This phenomenon is decisive for the disease's pathogeny. 
Some non-steroidal anti-inflammatory drugs (NSAID) such as ibuprofen, indomethacin, sulindac, diclofenac (and not others such as acetylsalicylic acid, naproxen, celecoxib and rofecoxib) have shown regulating effects on $\beta \mathrm{A}_{42}$ production. The mechanism for this action seems to be varied [67], but it mainly consists of the allosteric modulation of the $\gamma$-secretase that hydrolyzes the APP, without acting on notch or other substrates $[68,69]$. Up to this point, no randomized prospective trials obtaining a significant favorable modification in the evolution of AD through NSAID treatment have been published. Glucocorticoids and celecoxib produce an amyloidogenic effect in some cases, so that it is not probable that their research in AD will continue [70-72]. In a broad epidemiological study a reduction of the risk of AD in individuals with the Apo E- $\varepsilon 4$ allele who have been treated with NSAID was observed, but there were no differences according to the fact that the NSAID received was or was not a $\beta \mathrm{A}_{42}$-reducer [73-75]. On the other hand, knowing the side effects of NSAID (especially gastrointestinal effects), it should be proven that, after long-term administration, the potential modifying effect of $\mathrm{AD}$ is not cut short by serious complications. One of the $\gamma$-secretase modulating NSAID without action on notch is flurbiprofen. In the phase-II trial it was observed that in the subset of patients with incipient AD $($ MMSE $=20-26)$ and high dose of the drug $(800 \mathrm{mg}$ bid $)$ significant improvement took place in functional autonomy and a positive tendency was also observed in cognition [76]. In the phase-III study, however, flurbiprofen failed to improve cognitive functioning or autonomy in daily activities.

Cholesterol increases $\beta$ A-production from APP and, in turn, such increase reduces cholesterol synthesis. Statins inhibit lipidation of $\beta$-secretases and through the isoprenylation of GTPase, which takes part in secretases assembly to the APP, reduce $\beta$ A-production $[77,78]$. For this purpose, it is possible that the statins which cross the blood-brain barrier (simvastatin, lovastatin) are more effective than some others such as pravastatin or atorvastatin $[79,80]$. They also have anti-inflammatory effects [81] and some of them, such as lovastatin, produce a glycogen-synthase-kinase 3 (GSK-3 $\beta$ ) inhibitory effect [82], through which hyperphosphorylated tau protein is reduced and, in fact, less neurofibrillary tangles have been reported in patients who have previously taken statins [83]. The results from epidemiological studies and clinical trials regarding the risk to develop AD or modification of its evolution differ. Therefore, further evidence is needed before statins can be used as protectors against $\mathrm{AD}$ $[84,85]$. The lipid-lowering drug fenofibrate, unlike statins, has an amyloidogenic effect similar to that of cholesterol $[71,72]$.

Apart from their sexual function, gonadal steroids exert other functions. Estrogens facilitate APP processing through the non-amyloidogenic pathway, reduce tauhyperphosphorylation and oxidative stress, and exert a trophic stimulus on cholinergic neurons and other brain cells important in AD [86-91]. Epidemiological studies have observed lower incidence of $\mathrm{AD}$ in women who have received treatment with estrogens [92] and lower atrophy in hippocampal regions [93], although observational studies with negative results can also be found [94-96]. Among these, particular emphasis needs to be given to the Women's Health Initiative Memory (WHIMS) [94], a randomized double-blind study which followed up (through an average of 4 years) 4532 nondemented postmenopausal women older than 64 years, who underwent treatment with conjugated equine estrogen and medroxyprogesterone $(n=2229)$ or placebo $(n=2303)$. Out of the 61 women who developed dementia, 40 (66\%) belonged to the group of active treatment and 21 (34 $\%)$ to the placebo group, which means a hazard ratio for probable dementia of 2.05 , 45 vs 22 per 10000 person-years $(\mathrm{p}=0.01)$. Participants came from a broader study (Women's Health Initiative -WHI-) which was suspended in 2002 due to the incidence of adverse events. Discrepancy in the results of the studies is due to multiple reasons, although the main reason might be that estrogens slow the progression of $A D$ only if they act over a prolonged period of time in an early pre-clinical stage, when there is still no significant $\beta A$ accumulation. In fact, some researchers have observed that the administration of oestradiol to rats when $\beta_{42}$ has already been accumulated exacerbates neurodegeneration [97], and in short-term treatment [92] or in treatment of demented women [98] it no longer produces beneficial effects. In practice, we cannot prescribe this treatment in pre-clinical stages, due to the fact that we do not know markers for this stage. Besides, we should make use of a treatment whose long-term tolerability profile does not involve a high risk/benefit index. Emerging in this search for alternative drugs is the use of leuprorelin. AD patients show higher serum and brain levels of luteinizing hormone (LH), which facilitates APP processing through the amyloidogenic pathway [99]. Leuprorelin, analogous to the gonadotropin-releasing hormone $(\mathrm{GnRH}$ or LHRH), reduces LH and, in transgenic mice, gives rise to lower $\beta$ A-production and cognitive improvement [100]. In September 2005 a phase-III trial began, whose results have not been published yet.

Phenserine is an ACEI that reduces APPs- $\beta$ and $\beta$ A production [101] (see Fig. 5). In a preliminary study with 20 patients, cognitive and cortical activity improvement (PET) was observed [102]. However, in two phase-III trials no significant cognitive benefit was obtained. In a post-hoc analysis of the three existing phase-III studies, cognitive improvement was observed in patients who received higher doses $(15 \mathrm{mg} /$ day) for more than 12 months, but no significant difference was reached against placebo regarding clinical global impression.

Cerebrolysine is a nootropic agent which reduces apoptosis and facilitates neurogenesis within the hippocampal region in transgenic mice [103]. Through a kinase-inhibiting effect (on GSK-3 and cdk5) it reduces phosphorylated APP, that gives rise to lower $\beta$ A-production [104]. A metaanalysis of trials carried out so far points out that intravenous infusion 5 days a week for 4 weeks improves clinical global impression, although its effect on cognition and functional autonomy varies; in some studies it is no different than that obtained with placebo [105].

\section{II.B. Drugs to Reduce BA Aggregation}

There exist some synthetic peptides (beta-sheet breakers) -for instance, $A \beta 16-22 \mathrm{~m}$, iA $\beta 5$, iAb5p, iAb5p-A1, PAB3631-PI, SEN-304- that attempt to prevent and undo the $\beta$ folding which takes place in many $\beta \mathrm{A}$-fragments in order to reduce its aggregability and inhibit fibrillogenesis [106, 107]. Another strategy is the treatment with monoclonal antibodies aimed at the $\mathrm{N}$-terminal region of $\beta \mathrm{A}$ involved in fibrils precipitation; it obtains fibrillar disaggregation, giving 
back solubility to the peptide and eliminating its toxicity [108]. All these proceedings still have not reached advanced stages in human experimentation.

Tramiprosate (Alzhemed ${ }^{\circledR}$ ) is analogous to glycosaminoglycans which, through their joint to $\beta \mathrm{A}$, hinders its aggregation. Unfortunately, in the last phase-III trial no significant clinical efficacy was reported and some researchers noticed that it may increase tau-aggregation [109]. Lipocrine, a hybrid compound of tacrine and lipoic acid, blocks the catalytic binding site of acetylcholinesterase and $\beta \mathrm{A}$, giving rise to a reduction of $\beta \mathrm{A}$ aggregability as well as having antioxidant properties like the lipoic acid [110]. Colostrinin, derived from calostrum, solubilizes $\beta$ A-fibres and reduces its polymerization, besides having antioxidant properties. In studies against placebo, it has been observed that it leads to certain cognitive and functional stabilization [111]. Curcumin, a component of culinary curry, crosses the blood-brain barrier and hinders $\beta \mathrm{A}$ aggregation; it is also disaggregating and has anti-inflammatory and antioxidant properties [112]. In a double-blind placebo-controlled trial with 34 patients, no significant clinical differences were observed and $\beta \mathrm{A}_{40}$ serum levels did not vary either [113].

Some metals take part in intracellular physiological oxidoreductive activity. Their interaction with $\beta$ A has various effects. For instance, their bind to $\mathrm{Cu}^{++}$(and $\mathrm{Fe}^{+++}$to a lesser extent) facilitates the formation of toxic oligomers and the increase of oxidative activity and formation of free radicals, while the presence of $\mathrm{Zn}^{++}$displaces $\mathrm{Cu}^{++}$and exerts a protective effect [114]. Therapeutic strategies try to modulate the presence of these metals in the brain in order to reduce oxidative activity, or try to eliminate free radicals already formed by administering antioxidants. A zinc supplement in diet has been suggested, but experimentation points to its inadvisability [115]. Treatment with metal-chelating agents seems to be more plausible. Among the latter, clioquinol (PBT-1) did not obtain sufficiently positive result in the trial [116] and may produce visual alterations. $P B T-2$ is currently in phase-II of experimentation. It seeks to inhibit the formation of $\beta A$-oligomers and disaggregate amyloid plaques through promoting normal copper and zinc brain homeostasis.

A phase-II trial with $A Z D-103$ (scyllo-inositol, scyllocyclohexanehexol), which reduces $\beta$ A aggregation and neutralizes oligomers, has already begun. NAP (also known as AL-108), administered intranasally, has also reached phase-II in research as an octapeptide with $\beta$ A-antiaggregant and microtubule stabilizer properties. Memoquin has been mentioned in Section II.A as a multifunctional compound that reduces the $\beta \mathrm{A}$ aggregability promoted by acetylcholinesterase [63].

\section{II.C. Drugs to Stimulate BA Elimination}

A technique to eliminate $\beta \mathrm{A}$ is immunotherapy, which may be active ( $\beta \mathrm{A}$ is administered to stimulate the production of antibodies) or passive (anti- $\beta \mathrm{A}$ antibodies are administered). In the first case we find $A N 1792$, whose trial in humans was suspended due to the appearance of encephalitis. In the brain of autopsied patients who generated antibodies, lower than expected $\beta$ A density was observed, apart from activated microglia and persistence of neurofibrillary tangles [117]. Clinically, no significant improvement against pla- cebo was obtained [118] and greater loss of brain and hippocampal volume was observed through magnetic resonance [119]. The same dementia-progression rate was observed in patients showing $\beta \mathrm{A}$ reduction, perhaps because neuritic plaques are the final product of a neurotoxic process whose greatest responsibility may be attributed to amyloid oligomers, whose formation precedes plaque formation. On the other hand, a faster rate of progression was observed in patients with no amyloid reduction than in untreated patients, which adds fear to the use of this therapeutic technique. However, such line is still being researched; ACC 001 and CAD-106 (in phases II and I, respectively) are two formula of active immunotherapy that attempt to act without causing brain defensive reactions. Among monoclonal anti- $\beta \mathrm{A}$ antibodies we find AAB 001 (bapineuzumab). A study refers brain micro-hemorrhages in patients who underwent passive immunotherapy, so that further attention should be drawn to its tolerability [120]. The preliminary results of a phase-II double-blind trial with intravenous immunoglobulins against placebo in $24 \mathrm{AD}$ patients for 6 months, showed better evolution in clinical global impression $(p<0.001)$ but no significant difference was reached regarding cognition (paper presented by N. Relkin et al. at the $60^{\text {th }}$ Annual Meeting of the American Academy of Neurology, April 2008).

Insulin accelerates $\beta A$ intracerebral circulation and elimination, and increases of the brain insulin resistance have been reported in many AD patients. Showing insulin resistance during midlife increases the risk of suffering $A D$ in subsequent years [121]. For this reason, the effectiveness of rosiglitazone has been researched; it reduces such resistance, is anti-inflammatory and stimulates mitochondrial biogenesis [122]. In a double-blind placebo-controlled trial $(n=518)$ cognitive improvement was only observed in the group of patients without the APO E $\varepsilon 4$ allele [123] and, in another study in which 30 patients were followed up for 6 months, those patients who received rosiglitazone did not show the diminution of $\beta \mathrm{A}$ in cerebrospinal fluid shown by the placebo group [124]. It seems to be necessary to widen experimentation with this substance as well as to check to what extent it produces in AD patients the same cardiovascular events it causes in diabetes patients [125]. Intranasal insulin has also been researched since it increases glucose availability in the brain, scarcely affecting its peripheral metabolism. In a placebo-controlled study $(n=25)$ treated patients showed better results regarding attention, memory and functional capacity [126]. As it occurs with rosiglitazone, it seems that the treatment is only effective in patients without the APO E $\varepsilon 4$ allele [127].

Curcumin, already mentioned in the previous section, binds to amyloid deposits and facilitates their elimination [112], although such action produced no significant clinical or serum $\beta$ A changes in a narrow trial [113].

Stimulation of plasminogen through tPA (tissue plasminogen activator) and the subsequent generation of plasmin reduces $\beta$ A formation and accelerates its elimination. For this reason, the possible usefulness of a treatment with PAI- 1 $(\mathrm{PAI}=$ plasminogen activator inhibitor) or $T G B-\beta 1$ (PAI-1 inductor) inhibitors or antagonists has been raised [128]. It has also been observed, however, that tPA induces the activation of GSK3 and, thus, greater tau-phosphorylation and 
neurotoxicity [129], so that the application of the above mentioned treatment may turn out to be risky.

Somatostatin modulates $\beta \mathrm{A}$-proteolysis mediated by neprilysin. In $\mathrm{AD}$, a somatostatin depletion facilitates $\beta \mathrm{A}$ accumulation. Drugs analogous to somatostatin (e.g. octreotide, ineffective in AD [130]), drugs which stimulate somatostatin release (for instance FK962, ineffective in a phase-II study) or drugs that act on its receptors, have been considered as candidates for experimentation aimed at improving the evolution of $\mathrm{AD}[131,132]$.

\section{II.D. Drugs to Reduce Neurofibrillary Degeneration}

Phosphorylated tau-protein binds to microtubules in order to facilitate their assembly, assuring the stability of the neural cytoskeleton. A correct phosphorylation requires a balance between the action of some kinases and phosphatases (especially GSK 3, cyclin-dependent protein kinase cdk5 - and protein-phosphatase $2 \mathrm{~A}-\mathrm{PP}-2 \mathrm{~A}-$-). GSK-3 $\beta$ plays a more relevant role than GSK- $3 \alpha$ in tau-phosphorylation, while the opposite occurs in APP processing to produce $\beta \mathrm{A}$. There is a GSK3 hypothesis of $A D$, according to which GSK-3 hyperactivity would be responsible for excessive $\beta$ A-production, periplaque microglia reaction and tauhyperphosphorylation. The latter, in turn, alters axonal transport, reduces the firmness of the cytoskeleton and induces the formation of neurofibrillary tangles [133]. An increase of endogenous inhibitors of PP-2A in AD has also been observed [134]. From a therapeutic viewpoint, it may be possible to inhibit GSK-3 or stimulate PP-2A, having identified subgroups of AD that may respond differently to these treatments [135]. Molecules with anti-GSK3 properties have been investigated in antineoplastic research, some of them being suggested to be applied to $\mathrm{AD}$, such as certain derivatives of indirubin [136], paullones [137], aloisines [138] or hymenialdisine [139]. Lithium and valproic acid have also been studied as GSK-3 inhibitors [140]. Valproate does not act on cortical GSK-3 [141] and, regarding lithium, some researchers think that it acts on GSK-3 $\beta$ and GSK-3 $\alpha$ and, due to its action on the latter, reduces $\beta$ A-production [142], while other researchers have observed $\beta A$-increases, which they attribute to a mechanism not related to GSK3 [143].

Among the multifunctional drugs with anti-GSK3 action, the afore-mentioned lovastatin [82] and thiadiazolidinones can be cited. The latter have anti-inflammatory and neuroprotective effect, partly because they activate nuclear peroxisome proliferator-activated receptors (PPAR) and partly because they inhibit GSK-3 $\beta$ [144, 145].

Nicotinamide (vitamin B3) produces cognitive improvement and phospho-tau reduction, mediated by its action on kinases, in transgenic mice (paper presented by KN Green et al. at the $60^{\text {th }}$ Annual Meeting of the American Academy of Neurology, April 2008). Therefore, it is a candidate molecule to be valued in AD patients, maybe as a complement to other treatments.

On the other hand, memantine stimulates PP-2A, thus contributing to the reduction of neurofibrillary degeneration $[39,40]$.

Paclitaxel, which is related to taxol, stimulates tubulin polymerization and acts as a microtubule stabilizer [146].

Currently, active immunotherapy with phosphorylated tau is under research. The generation of antibodies that re- duce neurofibrillary tangles with no inflammatory reaction has been observed in animals [147].

\section{II.E. Drugs to Reduce Excitotoxicity and/or Oxidative Stress}

Glutamate excess in synapses in diseased brain areas has deleterious effects for the cell (excitotoxicity). It causes excessive entrance of calcium into the cell, with an increase of the oxidative activity and functional damage to mitochondrias. LY451395, a modulator of glutamate AMPA receptors, did not reach significant clinical differences against placebo in a trial [148]. Dimebolin hydrochloride (Dimebon ${ }^{\circledR}$ ) is an acetyl and butyrylcholinesterase inhibitor that blocks the entrance of calcium through L-type (voltage-dependent) and NMDA (glutamatergic) channels, having symptomatic and neuroprotective effects [149, 150], and modulating mitochondrial membrane pores, so that it helps preserve mitochondrial function [151]. In a one-year-long double blind, placebo-controlled, phase-II study with 183 patients, significant improvements in cognition, behavior and functional autonomy were observed [152]. Patients are currently being enrolled in a phase-III study (http://www.alzforum.org/ new/detail.asp?id=1590; http://www.medivation.com). Memantine is the antagonist drug of NMDA receptors that has given us the greatest amount of results within the field of AD. The reduction of excitotoxicity and of oxidative damage is one of its main functions [153]. Its proven symptomatic effect [5-10] and the fact of reducing tauhyperphosphorylation [39, 40] make it an interesting drug with which to treat AD. Anyway, it will be necessary to prove its possible modifying effect in AD evolution through trials specifically designed for such aim. Other newgeneration anti-NMDAs such as neramexane are currently being researched for neuroprotection in AD [154]. No significant differences were observed in a phase-III trial with 415 patients in which double-blind comparisons were established between a single anticholinesterase or a combination with neramexane; this research is ongoing with the administration of such drug as monotherapy against placebo.

Drugs with antioxidant action such as memoquin, lipocrine, colostrinin, curcumin, rosiglitazone, clioquinol or $P B T-2$ have already been mentioned in previous sections due to their multifunctional capacity. Some epidemiological and prospective studies observe lower AD incidence or progression in individuals taking vitamin $E$, preferably in combination with vitamin $C$ [155-157], but a Cochrane analysis does not find clear evidence of any beneficial effect [158]. Furthermore, a meta-analysis showed an increase of mortality in individuals taking more than $150 \mathrm{UI} /$ day of vitamin E [159]. Ginkgo biloba has antioxidant effects, but the most recent trials have failed to find any benefit on progression of cognitive impairment or AD [160-162]. Furthermore, such treatment is not free from a small risk of ischemic or hemorrhagic events [162, 163].

Melatonin has antioxidant and antiapoptotic properties, it increases mitochondrial energetic metabolism and reduces tau-hyperphosphorylation and $\beta$ A-formation and deposit [164, 165]. Moreover, its MT1 and MT2 receptors are altered in $\mathrm{AD}$ [166]. Experimentation in $\mathrm{AD}$ animal models leads us to think of a favorable clinical effect of melatonin, but no controlled extensive clinical trial have been carried out in humans in order to demonstrate if melatonin can mod- 
ify $\mathrm{AD}$ incidence or progression. Likewise, tacrinemelatonin hybrid molecules, which presumably would add the symptomatic effect of the anticholinesterase to the combination, are currently under research [167].

Studies developed with selegiline, an IMAO- $\beta$ with antioxidant properties, conclude that there is no justification to use it in AD patients [168]. Rasagiline has different aspects from selegiline that make it more attractive, apart from facilitating APP non-amyloidogenic processing [169]. AD research, however, seems to have moved towards a bifunctional molecule, ladostigil, that combines properties of rivastigmine and rasagiline [169, 170].

Higher cortisolemia and greater cortisol/DHEA (DHEA = dehydroepiandrosterone, antiglucocorticoid) ratio are observed in the plasma of some AD patients than in healthy individuals of the same age [171], which may facilitate cognitive impairment and hippocampal atrophy [172]. For this reason, DHEA has been considered as a potential treatment of $\mathrm{AD}$, since it reduces excitotoxicity and has antioxidant properties [173, 174]. In a narrow double-blind placebocontrolled study of DHEA, no significant differences were observed either in cognitive performance or in clinical global impression [175].

Huperzine $A$, an alkaloid of the herb huperzia serrata used in Chinese traditional medicine, has antioxidant properties, is an ACEI, stimulates muscarinic and neuronal growth factor receptors, increases APP non-amyloidogenic processing, protects against apoptosis and cytotoxicity caused by $\beta A$, glutamate or ischemia. In clinical trials carried out in China, it has been observed that it produces memory improvement in elderly people with amnesic disorder and in AD patients or those with vascular dementia, probably due to its ACEI action [176]. It would be desirable to see if its neuroprotective effects lead to favorable modifications in AD evolution. It is currently under a phase-II trial in USA.

A technique to increase the efficacy of already existing treatments is dimmer's synthesis. Among them we can mention bis-tacrine (tacrine dimmer) and bis-HupA or bis-hupyridone (dimmer of a fraction of huperzine A). Bistacrine also has BACE-1 inhibitory action and blocks NMDA receptors, that provides it with an additional neuroprotective action [177].

Polyunsaturated fatty acids facilitate neuroplasticity in neuronal membranes and synaptic transmission, have antioxidant and antiapoptotic properties, protect against excitotoxicity, inhibit the production of proinflammatory cytokines and, furthermore, reduce $\beta \mathrm{A}$ and phospho-tau production while improving learning capacity [178-182]. These fatty acids are not synthesized in the brain but come from food. In animal models and in humans it has been observed that diets rich in these substances or containing a supplement of them (omega-3 fatty acids, docosahexaenoic acid) reduce AD risk, especially in individuals who do not carry the Apo E $\varepsilon 4$ allele [183, 184], though some researchers have obtained negative results [185]. These products are available in the market as nutritional supplement. In a small group of AD patients a significantly favorable effect was observed in cognition (MMSE) from treatment with omega-3 fatty acids plus lipoic acid -antioxidant- (paper presented by L. Shinto et al. at the $60^{\text {th }}$ Annual Meeting of the American Academy of Neurology, April 2008).
Propentofylline is a xanthinic derivative which inhibits adenosine reuptake and phosphodiesterase. Among other actions, it reduces the production of free radicals and microglia activation, stimulates the synthesis and release of the nerve growth factor, facilitates APP non-amyloidogenic processing and decreases activated GSK-3 $\beta$ [186]. The results from phase-II and III trials point out that improvement in cognition, global function and functional autonomy is achieved and the follow-up of individuals who left the study seems to indicate that propentofylline slows down AD progression [187, 188]. In a phase-II study it was observed that brain metabolism (PET) increased after stimulation with a verbal task [189]. However, the authors of the Cochrane analysis point out that part of the data obtained through experimentation has not been published by the researchers and that much of the published data does not discriminate between different etiological types of dementia [188]. The research of this drug in relation to AD has been interrupted.

\section{II.F. Cell Therapy, Regenerative Medicine}

The incorporation of multipotential cells into the brain to stimulate neurogenesis in brain areas affected by AD (cell therapy) is a promising field. In animal models, implanted cells undergo intracerebral migration, differentiate themselves and improve memory [190]. For multiple reasons, the treatment is complex. The optimum source of stem cells that should be implanted is a question currently under public and scientific debate. The implantation technique needs to minimize risks. The implanted cells should not only survive but they also need proliferate, differentiate themselves by acquiring the specialization of affected cells and, finally, integrate themselves in complex cell networks in order to make their function operative. The use of out-of-patient multipotential cells (obtained from embryonic tissues, bone marrow, umbilical cord or placenta, for example) may induce rejection more easily than using the patient's own cells. In this sense, nerve cells have already been obtained from the patient's skin or bone marrow [191]. Embryonic stem cells have great replication capacity but they also present a great risk for developing tumors [192]. An alternative consists of activating (through genetic modifications or nerve growth factors) stem cells which are inactive whether in the own brain or in another part of the body [191, 193, 194]. Moreover, this procedure avoids the surgery required to implant exogenous cells. A recent trial showed that stem cells administered intravenously to transgenic mice cross well the blood-brain barrier; this might solve the problems associated with implantation surgery [195]. On the other hand, if there is an excess of APP in the brain, multipotential cells become glial cells to a greater extent than neuronal cells (thus producing gliosis), so that it would be necessary to modulate the presence of APP. A variant of phenserine has been tested with such aim [196, 197]. Interesting to note is the study in which 6 AD patients were followed up for 22 months after being implanted genetically-modified autologous skin fibroblasts in order to produce human nerve growth factor. The results range from a slower progression of cognitive impairment to an increase of cerebral cortical activity (PET) [198].

Many of us, who are engaged in neurological clinical practice and are mere observers of this matter, suspect that other problems are much more difficult to solve: 
a) $\quad \mathrm{AD}$ affects extensive associative and limbic areas of the brain as well as multiple subcortical gray-matter nuclei, which are the source of several neurotransmitters. Therefore, treatment with stem cells should act on various points and new cells should acquire varied specializations.

b) When associative areas formed by axon and dendrite tangles of varied origin are affected, it seems difficult for newly arrived cells to properly integrate their new tentacles (both structurally and functionally) in such complex networks.

c) Stem cells which begin to specialize within the diseased brain will have to do it in a hostile environment. When the first symptoms appear, several alterations - which include the activation of microglia and other inflammatory elements, accumulation of neuroexcitatory aminoacids, deposit of proteins with neurotoxic effects, etc. - have already been taking place in the brain for many years and many surviving cells are also functionally damaged, all of which hinders the development of implanted cells.

In short, it seems more feasible to introduce cells into the brain intending to stimulate the production of neuronal growth factors or the secretion of deficient neurotransmitters, instead of cells that attempt to substitute degenerated brain tissue.

On the other hand, knowing the possibility of creating transgenic mice, we may attempt to correct mutations and polymorphisms that cause the disease or increase the risk to suffer from it. This genetic manipulation is very difficult to apply in sporadic AD, since there are many genetic risk elements (many of which are still unknown) and difficulties of an ethical nature will be found in monogenic hereditary forms. In any case, what today seems to be utopian may become a pleasant reality within the not-too-distant future. However, the path currently followed by cell therapy and genetic manipulation and engineering to treat degenerative dementia may prove to be both thorny and lengthy.

\section{REFLECTIONS ON THE DIFFICULTIES TO DEVELOP TREATMENTS THAT MODIFY THE EVOLUTION OF THE ALZHEIMER'S DISEASE}

Historically, in 1976 the loss of cerebral cholinergic neurons in AD had already been detected [199], in 1979 an ACEI (physostigmine) had been tested [200, 201], in 1981 we knew the results of a study with tacrine [202] and in 1993 the same drug was approved by the FDA as a symptomatic treatment for AD. Technological and communication advances made us believe that the time intervals for approving new treatments would become progressively shorter. However, research on drugs which modify the course of the disease is considerably different from that which searches for symptomatic medication. For instance, in 1991 the relation between secretases and $\beta A$-synthesis was already known [203]. In 1999 it was established that presenilins are $\gamma$ secretases [204] and the characteristics of BACE $(\beta$ secretase) were detailed [205]. A year later the race had already begun to synthesize secretase inhibitors to treat AD. Unlike previous predictions it might have been foreseen, in 2008 there is still a long way to go to ready these molecules for market, if they do finally demonstrate their efficacy. As the first decade of the new century is coming to an end, none of the treatments aimed at modifying AD progression seems to be at the point of imminent approval, despite the hundreds of molecules now in different research stages, some of which are presented as effective in international meetings and congresses. What reasons can we give for our present situation?

Research on drugs that are directed toward brain neurotrophism, neuroprotection or neuroplasticity in AD patients, and that try to significantly reduce the progression of its preclinical process or clinical course, differs from the research that is necessary to prove the symptomatic effect of a drug [22]. Some difficulties are shared by all therapeutic research such as the possibility that effectiveness and tolerability (theoretically foreseeable or even observed in trials with animals) are not evident when experimenting with humans. When investigating drugs that modify the evolution of AD other difficulties are to be expected (Table 4).

When the first symptoms appear in AD patients, the underlying neuropathological process has been brewing for decades [206]. If a drug could stop or slow down the physiopathological phenomena that provoke cell dysfunction and death in certain parts of the brain, it should be applied in preclinical stage with the aim of avoiding or delaying the symptom's appearance. Since AD is a disease that mainly appears at advanced ages, when mortality due to other causes is already very present, an extension of the preclinical stage would mean that many patients would not even show the first symptoms and some others would not go beyond the stage of mild cognitive impairment. That is, prevalence of dementia due to AD would be reduced. However, carrying out research on humans in the preclinical stage turns out to be extremely difficult. If we exclude known and asympto-

Table 4. Difficulties for the Development of Drugs that Modify the Evolution of AD

\begin{tabular}{|ll|}
\hline - & Scarcity of AD markers in preclinical stage \\
\hline - & Scarcity of markers of AD phenotypes \\
\hline - & Difficulty to obtain molecules with selective action on diseased cells \\
\hline - & Most drugs will have weak effects since they act only on a part of the etiopathogenic chain \\
\hline - & It is necessary to distinguish between symptomatic action and changes in the course of the disease \\
\hline - & Need of a prolonged period of observation to prove delay in progression \\
\hline - & Need to work with very wide human samples to achieve clinical evidence and statistical signification \\
\hline - & High economic cost of trials designed to ascertain modifications in AD evolution \\
\hline
\end{tabular}


matic carriers of a mutation producing familial AD, we do not have available suitable preclinical markers for the rest of the population. Besides, on the assumption that research took place in this group of pre-patients, the results could only be evaluated by observing the progression of histopathological lesions, since no clinical or biochemical markers -useful to create a base to see the effectiveness of the researched drugare known in such preclinical stages. Even if we assume that changes in the concentration of lesions are found (for instance, by using PET with specific markers such as Pittsburgh Compound B -PIB-) there would be little certainty that molecular and cellular pathology had been really delayed. It can be possible that $\beta$ A-oligomers be harmful and plaques only constitute residues of an already-finished pathological phenomenon, so that a drug might reduce the concentration of amyloid plaques without obtaining any favorable clinical result.

When dementia is present it is less difficult to identify patients with probable AD. Neuropsychological markers, phospho-tau and $\beta \mathrm{A}_{42}$ alterations in cephalospinal fluid, hypoactivity of posterior cingulum extendable to other associative temporoparietal areas (through PET or SPECT) and noticeable atrophy in hippocampal regions (through magnetic resonance) allow practitioners to diagnose $\mathrm{AD}$ with high reliability, at least in typical cases without other alterations associated to it. However, AD is a heterogeneous disease. The genes that cause or facilitate its development are varied (Table 2) and, maybe for this reason, varied phenotypes are found in practice (frontal variant of $\mathrm{AD}$, posterior cortical atrophy, AD starting with progressive aphasia or apraxia, AD with Lewy bodies). It is possible that, when researching drugs aimed at interfering in $\mathrm{AD}$ pathogenic sequence, it is valuable to know the patient's phenotype supposing that, due to the disease's heterogeneity, the effectiveness of the drug may differ within each subtype. Thus, it would be advisable to investigate within homogeneous, well-characterized groups. Regarding this aspect, we find lack of criteria and markers that identify AD phenotypes in a reliable way and, furthermore, we do not know in detail the existing differences among them at molecular and cellular level. If we accept simple clinical selection of phenotypes, the fact of working with subgroups would increase the difficulty of reaching sufficient sample sizes, which should be quite large in this kind of research, as it will be commented on later.

If drugs act by interfering in the activities of the diseased cells, in many cases they generate adverse effects, because they may also interfere with the activities of healthy cells or because they may bear unnecessary actions for the treatment of the disease. Such is the case of many gamma-secretase inhibitors, which not only reduce APP hydrolysis but also that of many other substrates, thus producing undesirable side effects. Another example can be found in memantine; due to its voltage-dependent and fast blocking-unblocking mechanism of action, it does not have problems related to tolerability, while other NMDA receptor antagonists previously researched (dizocilpine, phencyclidine, ketamine) produced severe adverse effects since they block these receptors in a more indiscriminate and permanent manner [4, 207]. Therefore, drugs characterized by high selectivity should be created in order to act only on something that works badly and only in ill cells. This process of increasing selectivity is time consuming and delays the availability of effective and well-tolerated drugs.

The expected effect of new treatments is the reduction of disease progression, although in many cases symptomatic improvement takes place simultaneously. In these situations, it is necessary to distinguish between both effects in order to demonstrate that the treatment modifies disease evolution. Techniques available for such an aim were described in a previous section of this article. Finding a difference becomes progressively more difficult as less time is available for observation. Regarding modification of disease course, there should be found not only statistical differences against placebo regarding clinical parameters, but also evidence of a measurable slowing effect (for instance, prolongation of the duration of dementia stages or the time of survival).

A low effectiveness of these drugs is possible, as they do not act on the whole etiopathogenic sequence, which means that it is going to be difficult to prove significant differences against patients who do not follow this treatment. If a drug were highly effective, it might be sufficient to show that the progression slope (throughout a period probably no shorter than 18 months) is significantly lower than that observed in

Table 5. Selection of Treatments Investigated to Modify the Course of AD. Multifunctional Drugs can be Found in More than One Section

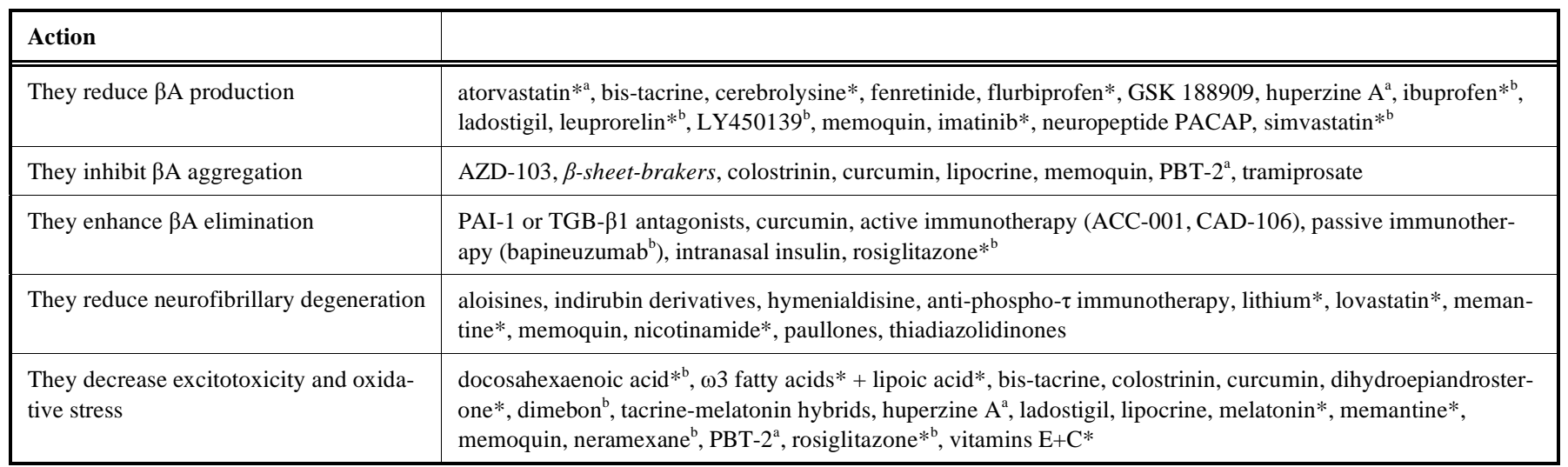

$\mathrm{PAI}=$ plasminogen activator inhibitor. TGB: transforming grow factor .

*: Currently marketed.

In phase-II (a) or phase-III (b) research, according to http://www.alzforum.org/drg/drc/default.asp [13.Nov.2008]. 
the control group $[19,21]$. However, in most cases it is probable that, in order to prove effectiveness, it is necessary to test the drug during several years in a large number of patients (several thousands of them, if we keep in mind the need to reach evidence as quickly as possible, obtaining non-intense benefit, and that a progressive loss of individuals is foreseeable throughout the follow-up process). The consequence of these requirements is a high cost that few companies are capable of assuming.

In order to lessen difficulties related to the scarce effectiveness of these drugs, the following strategies have been conceived:

a) Searching for drugs which act on items close to the origin of the pathogenic cascade (e. g., $\beta$ - or $\gamma$ secretase inhibitors), expecting to achieve greater effectiveness than that obtained with those which counteract an intermediate or final element of such a sequence (e. g., antioxidant substances or drugs which help eliminate amyloid plaques).

b) Synthesizing products active in several aspects of pathogeny (examples shown in Table 5).

c) Creating drugs with both neuroprotective and symptomatic effects (Table 1).

d) Testing the effectiveness of cocktails of presumablycomplementary substances. This option would turn out to be operatively more feasible if commercialized drugs, with already contrasted tolerability (see Table 5), were associated to one of the new molecules that have shown good tolerability and results, although not good enough for its approval.

In another sense, the incorporation of pharmacogenomics into clinical practice within the next years is foreseeable. It may not be very useful in discovery new treatments, but it may help optimize the use of available drugs. Certain genotypes or polymorphisms condition qualitative aspects of the drugs' target molecules or aspects related to their metabolism or other elements of the pathogenic chain, so that knowing them allows identifying subgroups of responders and/or non-responders in a certain treatment, or indicating those with good or bad tolerability. Let us consider some examples:

Carriers of polymorphism rs733722 of the gene which codifies ChAT (choline-acetyltransferase) show greater response to treatment with ACEI [208].

- $\quad$ Patients whose GST gene (glutathione-S-transferase encoder) does not produce M1 or T1 isozymes suffer greater risk to develop hepatotoxicity if they take tacrine [209].

- Genotype CYP2D6 influences the plasmatic concentration and the effectiveness of donepezil [210]

- Patients without the $\mathrm{K}$ allele in the butyrylcholinesterase gene show greater response and less adverse effects when treated with rivastigmine [211].

- $\quad$ Certain alleles of pro-inflammatory genes may detect AD patients suitable to be treated with antiinflammatories [212].
- Certain changes in the presenilin-1 encoding gene modify the antiamyloidogenic effect of anti-inflammatories. Mutations in exon-9 of PSEN1- $\delta$ remarkably reduce the efficacy of NSAIDs, while $P S E N 1-\mathrm{M} 146 \mathrm{~L}$ and $A P P-\mathrm{V} 717 \mathrm{~F}$ mutations increase their effect [213, 214].

- The PS1-L166P mutation induces ineffectiveness of LY-411575 ( $\gamma$-secretase inhibitor) [214].

- In a study with rosiglitazone, favorable results were only achieved in patients without the allele $A P O E \& 4$ [123].

In summary, the race to develop treatments that modify the evolution of AD has obstacles and may produce a general impression of slowness, but it is unstoppable. The efforts carried out in order to solve the difficulties are huge and highly expensive, but they are not going to be in vain. Any drug that slows down the progression of AD will immediately have favorable repercussions on the disease's prevalence and, in an ageing world, it will mean a great step in improving the prospects of health and wellbeing.

\section{ABBREVIATIONS}

\begin{tabular}{|c|c|c|}
\hline ACEI & $=$ & Acetylcholinesterase inhibitors \\
\hline $\mathrm{AD}$ & $=$ & Alzheimer's disease \\
\hline APP & $=$ & Amyloid precursor protein \\
\hline$\beta A$ & $=$ & Beta-amyloid \\
\hline BACE & $=$ & $\beta$-site APP cleaving enzyme \\
\hline DHEA & $=$ & Dihydroepiandrosterone \\
\hline FDA & $=$ & Food and Drug Administration \\
\hline GSK & $=$ & Glycogen synthase kinase \\
\hline I-BACE & $=$ & BACE inhibitors \\
\hline MMSE & $=$ & Folstein minimental state examination \\
\hline NSAID & $=$ & Non-steroidal anti-inflammatory drugs \\
\hline PET & $=$ & Positron emission tomography \\
\hline PP-2A & $=$ & Protein-phosphatase 2A \\
\hline
\end{tabular}

\section{REFERENCES}

[1] Birks J. Cholinesterase inhibitors for Alzheimer's disease. Cochrane Database Syst Rev 2006; (1): CD005593.

[2] Ritchie CW, Ames D, Clayton T, Lai R. Metaanalysis of randomized trials of the efficacy and safety of donepezil, galantamine, and rivastigmine for the treatment of Alzheimer disease. Am J Geriatr Psychiatry 2004; 12: 358-69.

[3] Takeda A, Loveman E, Clegg A, et al. A systematic review of the clinical effectiveness of donepezil, rivastigmine and galantamine on cognition, quality of life and adverse events in Alzheimer's disease. Int J Geriatr Psychiatry 2006; 21: 17-28.

[4] Johnson JW, Kotermanski SE. Mechanism of action of memantine. Curr Opin Pharmacol 2006; 6: 61-7.

[5] Wilkinson D, Andersen HF. Analysis of the effect of memantine in reducing the worsening of clinical symptoms in patients with moderate to severe Alzheimer's disease. Dement Geriatr Cogn Disord 2007; 24: 138-45.

[6] McShane R, Areosa Sastre A, Minakaran N. Memantine for dementia. Cochrane Database Syst Rev 2006; (2): CD003154.

[7] Maidment ID, Fox CG, Boustani M, Rodríguez J, Brown RC, Katona CL. Efficacy of memantine on behavioral and psychological symptoms related to dementia: a systematic meta-analysis. Ann Pharmacother 2008; 42: 32-8. 
[8] Gauthier S, Loft H, Cummings J. Improvement in behavioral symptoms in patients with moderate to severe Alzheimer's disease by memantine: a pooled data analysis. Int J Geriatr Psychiatry 2007; 23: $537-45$.

[9] Cummings JL, Schneider E, Tariot PN, Graham SM. Memantine MEM-MD-02 Study Group. Behavioral effects of memantine in Alzheimer disease patients receiving donepezil treatment. Neurology 2006; 67: 57-63.

[10] Winblad B, Jones RW, Wirth Y, Stöffler A, Möbius HJ. Memantine in moderate to severe Alzheimer's disease: a meta-analysis of randomised clinical trials. Dement Geriatr Cogn Disord 2007; 24 : 20-7.

[11] Bakchine S, Loft H. Memantine treatment in patients with mild to moderate Alzheimer's disease: results of a randomised, doubleblind, placebo-controlled 6-month study. J Alzheimers Dis 2007; 11: 471-9.

[12] Pomara N, Ott BR, Peskind E, Resnick EM. Memantine treatment of cognitive symptoms in mild to moderate Alzheimer disease: secondary analyses from a placebo-controlled randomized trial. Alzheimer Dis Assoc Disord 2007; 21: 60-4.

[13] Peskind ER, Potkin SG, Pomara N, et al. Memantine treatment in mild to moderate Alzheimer disease: a 24-week randomized, controlled trial. Am J Geriatr Psychiatry 2006; 14: 704-15.

[14] Jones RW, Bayer A, Inglis F, Barker A, Phul R. Safety and tolerability of once-daily versus twice-daily memantine: a randomised, double-blind study in moderate to severe Alzheimer's disease. Int J Geriatr Psychiatry 2007; 22: 258-62.

[15] Ott BR, Blake LM, Kagan E, Resnick M, for the memantine MEMMD-11AB Study Group. Open label, multicenter, 28-week extension study of the safety and tolerability of memantine in patients with mild to moderate Alzheimer's disease. J Neurol 2007; 254: 351-8.

[16] Braak H, Braak E. Neuropathological stageing of Alzheimerrelated changes. Acta Neuropathol (Berl) 1991; 82: 239-59.

[17] Thal DR, Rub U, Orantes M, Braak H. Phases of A $\beta$-deposition in the human brain and its relevance for the development of AD. Neurology 2002; 58: 1791-800.

[18] Mori E, Hashimoto M, Krishnan KR, Doraiswamy PM. What constitutes clinical evidence for neuroprotection in Alzheimer disease: support for the cholinesterase inhibitors? Alzheimer Dis Assoc Disord 2006; 20 (2 suppl 1): S19-26.

[19] Vellas B, Andrieu S, Sampaio C, Wilcock G. For the European Task Force group. Disease-modifying trials in Alzheimer's disease: a European task force consensus. Lancet Neurol 2007; 6: 56-62.

[20] Mani RB. The evaluation of disease modifying therapies in Alzheimer's disease: a regulatory viewpoint. Statist Med 2004; 23 : 305-14.

[21] Bodick N, Forette F, Hadler D, et al. Protocols to demonstrate slowing of Alzheimer disease progression. Position paper from the International Working Group on Harmonization of Dementia Drug Guidelines. The Disease Progression Sub-Group. Alzheimer Dis Assoc Disord 1997; 11 (suppl 3): 50-3.

[22] Broich K. Outcome measures in clinical trials on medicinal products for the treatment of dementia: a European regulatory perspective. Int Psychogeriatr 2007; 19: 509-24.

[23] Lopez OL, Becker JT, Saxton J, Sweet RA, Klunk W, DeKosky ST. Alteration of a clinically meaningful outcome in the natural history of Alzheimer's disease by cholinesterase inhibition. J Am Geriatr Soc 2005; 53: 83-7.

[24] Kimura M, Akasofu S, Ogura H, Sawada K. Protective effect of donepezil against Abeta (1-40) neurotoxicity in rat septal neurons. Brain Res 2005; 1047: 72-84.

[25] Takada-Takatori Y, Kume T, Sugimoto M, Katsuki H, Sugimoto H, Akaike A. Acetylcholinesterase inhibitors used in treatment of Alzheimer's disease prevent glutamate neurotoxicity via nicotinic acetylcholine receptors and phosphatidylinositol 3-kinase cascade. Neuropharmacology 2006; 51: 474-86.

[26] Arias E, Gallego-Sandín S, Villarroya M, García AG, López MG. Unequal neuroprotection afforded by the acetylcholinesterase inhibitors galantamine, donepezil, and rivastigmine in SH-SY5Y neuroblastoma cells: role of nicotinic receptors. J Pharmacol Exp Ther 2005; 315: 1346-53.

[27] Meunier J, Ieni J, Maurice T. The anti-amnesic and neuroprotective effects of donepezil against amyloid $\beta_{25-35}$ peptide-induced toxicity in mice involve an interaction with the $\sigma_{1}$ receptor. Br J Pharmacol 2006; 149: 998-1012.
[28] Hashimoto M, Kazui H, Matsumoto K, Nakano Y, Yasuda M, Mori E. Does donepezil treatment slow the progression of hippocampal atrophy in patients with Alzheimer's disease? Am J Psychiatry 2005; 162: 676-82.

[29] Krishnan KR, Charles HC, Doraiswamy PM, et al. Randomized, placebo-controlled trial of the effects of donepezil on neuronal markers and hippocampal volumes in Alzheimer's disease. Am J Psychiatry 2003; 160: 2003-11.

[30] Winblad B, Wimo A, Engedal K, et al. For the Donepezil Nordic Study Group. 3-year study of donepezil therapy in Alzheimer's disease: effects of early and continuous therapy. Dement Geriatr Cogn Disord 2006; 21: 353-63.

[31] Eskander MF, Nagykery NG, Leung EY, Khelghati B, Geula C. Rivastigmine is a potent inhibitor of acetyl- and butyrylcholinesterase in Alzheimer's plaques and tangles. Brain Res 2005; 1060: 144-52.

[32] Venneri A, McGeown WJ, Shanks MF. Empirical evidence of neuroprotection by dual cholinesterase inhibition in Alzheimer's disease. Neuroreport 2005; 16: 107-10.

[33] Small GW, Kaufer D, Mendiondo MS, Quarg P, Spiegel R. Cognitive performance in Alzheimer's disease patients receiving rivastigmine for up to 5 years. Int J Clin Pract 2005; 59: 473-7.

[34] Farlow M, Potkin S, Koumaras B, Veach J, Mirski D. Analysis of outcome in retrieved dropout patients in a rivastigmine vs placebo, 26-week, Alzheimer disease trial. Arch Neurol 2003; 60: 843-8.

[35] Kihara T, Sawada H, Nakamizo T, et al. Galantamine modulates nicotinic receptor and blocks Abeta-enhanced glutamate toxicity. Biochem Biophys Res Commun 2004; 325: 976-82.

[36] Geerts H. Indicators of neuroprotection with galantamine. Brain Res Bull 2005; 64: 519-24.

[37] Raskind MA, Peskind ER, Truyen L, Kershaw P, Damaraju CV. The cognitive benefits of galantamine are sustained for at least 36 months: a long-term extension trial. Arch Neurol 2004; 61: 252-6.

[38] Rosi S, Vazdarjanova A, Ramírez-Amaya V, Worley PF, Barnes CA, Wenk GL. Memantine protects against LPS-induced neuroinflammation, restores behaviorally-induced gene expression and spatial learning in the rat. Neuroscience 2006; 142: 1303-15.

[39] Degerman Gunnarsson M, Kilander L, Basun H, Lannfelt L. Reduction of phosphorylated tau during memantine treatment of Alzheimer's disease. Dement Geriatr Cogn Disord 2007; 24: 247-52.

[40] Li L, Sengupta A, Haque N, Grundke-Iqbal I, Iqbal K. Memantine inhibits and reverses the Alzheimer type abnormal hyperphosphorylation of tau and associated neurodegeneration. FEBS Lett 2004; 566: 261-9.

[41] Reisberg B, Doody R, Stöffler A, et al. A 24-week open-label extension study of memantine in moderate to severe Alzheimer disease. Arch Neurol 2006; 63: 49-54.

[42] Atri A, Shaughnessy LW, Locascio JJ, Growdon JH. Long-term course and effectiveness of combination therapy in Alzheimer disease. Alzheimer Dis Assoc Disord 2008; 22: 209-21.

[43] Pollack SJ, Lewis H. Secretase inhibitors for Alzheimer's disease: challenges of a promiscuous protease. Curr Opin Invest Drugs 2005; 6: 35-47.

[44] Dewachter I, Van Leuven F. Secretases as targets for the treatment of Alzheimer's disease: the prospects. Lancet Neurol 2002; 1: 40916.

[45] Evin G, Sernee MF, Masters CL. Inhibition of gamma-secretase as a therapeutic intervention for Alzheimer's disease: prospects, limitations and strategies. CNS Drugs 2006; 20: 351-72.

[46] Pissarnitski D. Advances in gamma-secretase modulation. Curr Opin Drug Discov Devel 2007; 10: 392-402.

[47] Siemers ER, Quinn JF, Kaye J, et al. Effects of a gamma-secretase inhibitor in a randomized study of patients with Alzheimer disease. Neurology 2006; 66: 602-4.

[48] Netzer WJ, Dou F, Cai D, et al. Gleevec inhibits $\beta$-amyloid production but not Notch cleavage. PNAS 2003; 100: 12444-9.

[49] John V, Beck JP, Bienkowski MJ, Sinha S, Heinrikson RL. Human $\beta$-secretase (BACE) and BACE inhibitors. J Med Chem 2003; 46 4625-30.

[50] Rakover I, Arbel M, Solomon B. Immunotherapy against APP beta-secretase cleavage site improves cognitive function and reduces neuroinfalmmation in $\mathrm{Tg} 2576$ mice without a significant effect on brain abeta levels. Neurodegener Dis 2007; 4: 392-402.

[51] Hussain I, Hawkins J, Harrison D, et al. Oral administration of a potent and selective non-peptidic BACE-1 inhibitor decreases beta- 
cleavage of amyloid precursor protein and amyloid-beta production in vivo. J Neurochem 2007; 100: 802-9.

[52] Shimmyo Y, Kihara T, Akaike A, Niidome T, Sugimoto H. Flavonols and flavones as BACE-1 inhibitors: structure-activity relationship in cell-free, cell-based and in silico studies reveal novel pharmacophore features. Biochim Biophys Acta 2008; 1780: 81925.

[53] Ghosh AK, Kumaragurubaran N, Tang J. Recent developments of structure based $\beta$-secretase inhibitors for Alzheimer's disease. Curr Top Med Chem 2005; 5: 1609-22.

[54] Beswick P, Charrier N, Clarke B, et al. BACE-1 inhibitors part 3: identification of hydroxy ethylamines (HEAs) with nanomolar potency in cells. Bioorg Med Chem Lett 2008; 18: 1022-6.

[55] Clarke B, Demont E, Dingwall C, et al. BACE-1 inhibitors part 2: identification of hydroxy ethylamines (HEAs) with reduced peptidic character. Bioorg Med Chem Lett 2008; 18: 1017-21.

[56] Jennings LD, Cole DC, Stock JR, et al. Acylguanidine inhibitors of beta-secretase: optimization of the pyrrole ring substituents extending into the S1' substrate binding pocket. Bioorg Med Chem Lett 2008; 18: 767-71.

[57] Iserloh U, Pan J, Stamford AW, et al. Discovery of an orally efficaceous 4-phenoxypyrrolidine-based BACE-1 inhibitor. Bioorg Med Chem Lett 2008; 18: 418-22.

[58] Geschwindner S, Olsson LL, Albert JS, et al. Discovery of a novel warhead against beta-secretase through fragment-based lead generation. J Med Chem 2007; 50: 5903-11.

[59] Maillard MC, Hom RK, Benson TE, et al. Design, synthesis, and crystal structure of hydroxyethyl secondary amine-based peptidomimetic inhibitors of human beta-secretase. J Med Chem 2007; 50: 776-81.

[60] Stauffer SR, Stanton MG, Gregro AR, et al. Discovery and SAR of isonicotinamide BACE-1 inhibitors that bind beta-secretase in a $\mathrm{N}$-terminal 10s-loop down conformation. Bioorg Med Chem Lett 2007; 17: 1788-92.

[61] Luo Y, Bolon B, Kahn S, et al. Mice deficient in BACE1, the Alzheimer's $\beta$-secretase, have normal phenotype and abolished $\beta$-amyloid generation. Nat Neurosci 2001; 4: 231-2.

[62] Sankaranarayanan $\mathrm{S}$, Price $\mathrm{EA}, \mathrm{Wu} \mathrm{G}$, et al. In vivo beta-secretase 1 inhibition leads to brain Abeta lowering and increased alphasecretase processing of amyloid precursor protein without effect on neuroregulin-1. J Pharmacol Exp Ther 2008; 324: 957-69.

[63] Cavalli A, Bolognesi ML, Capsoni S, et al. A small molecule targeting the multifactorial nature of Alzheimer's disease. Angew Chem Int Ed 2007; 46: 3689-92.

[64] Sahin M, Karauzum SB, Perry G, Smith MA, Aliciguzel Y. Retinoic acid isomers protect hippocampal neurons from amyloid-beta induced neurodegeneration. Neurotox Res 2005; 7: 243-50.

[65] Goodman AB. Retinoid receptors, transporters, and metabolizers as therapeutic targets in late onset Alzheimer disease. J Cell Physiol 2006; 209: 598-603.

[66] Kojro E, Postina R, Buro C, Meiringer C, Gehrig-Burger K, Fahrenholz F. The neuropeptide PACAP promotes the alpha-secretase pathway for processing the Alzheimer amyloid precursor protein. FASEB J 2006; 20: 512-4.

[67] Heneka MT, O'Banion MK. Inflammatory processes in Alzheimer's disease. J Neuroimmunol 2007; 184: 69-91.

[68] Imbimbo BP. The potential role of non-steroidal anti-inflammatory drugs in treating Alzheimer's disease. Expert Opin Investig Drugs 2004; 13: 1469-81.

[69] Beher D, Clarke EE, Wrigley JD, et al. Selected non-steroidal antiinflammatory drugs and their derivatives target gamma-secretase at a novel site. Evidence for an allosteric mechanism. J Biol Chem 2004; 279: 43419-26.

[70] Green KN, Billings LM, Roozendaal B, McGaugh JL, LaFerla FM. Glucocorticoids increase amyloid-beta and tau pathology in a mouse model of Alzheimer's disease. J Neurosci 2006; 26: $9047-$ 56.

[71] Gamerdinger M, Clement AB, Behl C. Cholesterol-like effects of selective cyclooxigenase inhibitors and fibrates on cellular membranes and amyloid-beta production. Mol Pharmacol 2007; 72: 141-51.

[72] Kukar T, Murphy MP, Eriksen JL, et al. Diverse compounds mimic Alzheimer disease-causing mutations by augmenting Abeta42 production. Nat Med 2005; 11: 545-50.
[73] Szekely CA, Breitner JCS, Fitzpatrick AL, et al. NSAID use and dementia risk in the Cardiovascular Health Study: role of APOE and NSAID type. Neurology 2008; 70: 17-24.

[74] Szekely CA, Breitner JCS, Østbye T, et al. No advantage of A 342 -lowering NSAIDs for prevention of Alzheimer dementia in six pooled cohort studies. Neurology 2008; 70: 2291-8.

[75] Vlad SC, Miller DR, Kowall NW, Felson DT. Protective effects of NSAIDs on the development of Alzheimer disease. Neurology 2008; 70: 1672-7.

[76] Geerts H. Drug evaluation: (R)-flurbiprofen, an enantiomer of flurbiprofen for the treatment of Alzheimer's disease. IDrugs 2007; 10: 121-33.

[77] Ostrowski SM, Wilkinson BL, Golde TE, Landreth G. Statins reduce amyloid-beta production through inhibition of protein isoprenylation. J Biol Chem 2007; 282: 26832-44.

[78] Parsons RB, Farrant JK, Price GC, Subramaniam D, Austen BM. Regulation of the lipidation of beta-secretase by statins. Biochem Soc Trans 2007; 35: 577-82.

[79] Cibicková L, Palicka V, Cibicek N, et al. Differential effects of statins and alendronate on cholinesterases in serum and brain of rats. Physiol Res 2007; 56: 765-70.

[80] Riekse RG, Li G, Petrie EC, et al. Effect of statins on Alzheimer's disease biomarkers in cerebrospinal fluid. J Alzheimer Dis 2006; 10: 399-406.

[81] Höglund K, Blennow K. Effect of HMG-CoA reductase inhibitors on beta-amyloid peptide levels: implications for Alzheimer's disease. CNS Drugs 2007; 21: 449-62.

[82] Salins P, Shawesh S, He Y, et al. Lovastatin protects human neurons against Abeta-induced toxicity and causes activation of betacatenin-TCF/LEF signaling. Neurosci Lett 2007; 412: 211-6.

[83] Li G, Larson EB, Sonnen JA, et al. Statin therapy is associated with reduced neuropathologic changes of Alzheimer disease. Neurology 2007; 69: 878-85.

[84] Kuller LH. Statins and dementia. Curr Atheroscler Rep 2007; 9: 154-61.

[85] Zhou B, Teramukai S, Fukushima M. Prevention and treatment of dementia or Alzheimer's disease by statins: a meta-analysis. Dement Geriatr Cogn Disord 2007; 23: 194-201.

[86] Morinaga A, Hirohata M, Ono K, Yamada M. Estrogen has antiamyloidogenic effects on Alzheimer's beta-amyloid fibrils in vitro. Biochem Biophys Res Commun 2007; 359: 697-702.

[87] Alvarez-de-la-Rosa M, Silva I, Nilsen J, et al. Estradiol prevents neural tau hyperphosphorylation characteristic of Alzheimer's disease. Ann NY Acad Sci 2005; 1052: 210-24.

[88] Simpkins JW, Dykens JA. Mitochondrial mechanisms of estrogen neuroprotection. Brain Res Rev 2008; 57: 421-30.

[89] Nilsen J, Chen S, Irwin RW, Iwamoto S, Brinton RD. Estrogen protects neuronal cells from amyloid beta-induced apoptosis via regulation of mitochondrial proteins and function. BMC Neurosci 2006; 7: 74.

[90] Bora SH, Liu Z, Kecojevic A, Merchenthaler I, Koliatsos VE. Direct, complex effects of estrogens on basal forebrain cholinergic neurons. Exp Neurol 2005; 194: 506-22.

[91] Hajszan T, Milner TA, Leranth C. Sex steroids and the dentate gyrus. Prog Brain Res 2007; 163: 399-415.

[92] Zandi PP, Carlson MC, Plassman BL, et al. Hormone replacement therapy and incidence of Alzheimer disease in older women: the Cache County Study. JAMA 2002; 288: 2123-9.

[93] Hu L, Yue Y, Zuo PP, et al. Evaluation of neuroprotective effects of long-term low dose hormone replacement therapy on postmenopausal women brain hippocampus using magnetic resonance scanner. Chin Med Sci J 2006; 21: 214-8.

[94] Shumaker SA, Legault C, Rapp SH, et al. Estrogen plus progestin and the incidence of dementia and mild cognitive impairment in postmenopausal women: the Women's Health Initiative Memory Study: a randomized controlled trial. JAMA 2003; 289: 2651-62.

[95] Roberts RO, Cha RH, Knopman DS, Petersen RC, Rocca WA. Postmenopausal estrogen therapy and Alzheimer disease: overall negative findings. Alzheimer Dis Assoc Disord 2006; 20: 141-6.

[96] Petitti DB, Crooks VC, Chiu V, Buckwalter JC, Chui HC. Incidence of dementia in long-term hormone users. Am J Epidemiol 2008; 167: 692-700.

[97] Chen S, Nilsen J, Brinton RD. Dose and temporal pattern of estrogen exposure determines neuroprotective outcome in hippocampal neurons: therapeutic implications. Endocrinology 2006; 147: 530313. 
[98] Hogervorst E, Yaffe K, Richards M, Huppert F. Hormone replacement therapy to maintain cognitive function in women with dementia. Cochrane Database Syst Rev 2002 (3): CD003799.

[99] Webber KM, Perry G, Smith MA, Casadesus G. The contribution of luteinizing hormone to Alzheimer disease pathogenesis. Clin Med Res 2007; 5: 177-83

[100] Casadesus G, Webber KM, Atwood CS, et al. Luteinizing hormone modulates cognition and amyloid-beta deposition in Alzheimer APP transgenic mice. Biochim Biophys Acta 2006; 1762: 447-52.

[101] Shaw KT, Utsuki T, Rogers J, et al. Phenserine regulates translation of beta-amyloid precursor protein mRNA by a putative interleukin-1 responsive element, a target for drug development. Proc Natl Acad Sci USA 2001; 98: 7605-10.

[102] Kadir A, Andreasen N, Almkvist O, et al. Effect of phenserine treatment on brain functional activity and amyloid in Alzheimer's disease. Ann Neurol 2008; 63: 621-31.

[103] Rockenstein E, Mante M, Adame A, Crews L, Moessler H, Masliah E. Effects of Cerebrolysin on neurogenesis in an APP transgenic model of Alzheimer's disease. Acta Neuropathol 2007; 113: 26575.

[104] Rockenstein E, Torrance M, Mante M, et al. Cerebrolysin decreases amyloid- $\beta$ production by regulating amyloid protein precursor maturation in a transgenic model of Alzheimer's disease. $\mathbf{J}$ Neurosci Res 2006; 83: 1252-61.

[105] Wei ZH, He QB, Wang H, Su BH, Chen HZ. Meta-analysis: the efficacy of nootropic agent Cerebrolysin in the treatment of Alzheimer's disease. J Neural Transm 2007; 114: 629-34.

[106] Gordon DJ, Sciarretta KL, Meredith SC. Inhibition of betaamyloid(40) fibrillogenesis and disassembly of beta-amyloid(40) fibrils by short beta-amyloid congeners containing $\mathrm{N}$-methyl amino acids at alternate residues. Biochemistry 2001; 40: 8237-45.

[107] Permanne B, Adessi C, Fraga S, Frossard MJ, Saborio GP, Soto C. Are beta-sheet breaker peptides dissolving the therapeutic problem of Alzheimer's disease? J Neural Transm Suppl 2002; (62): 293301

[108] Solomon B. Anti-aggregating antibodies, a new approach towards treatment of conformational diseases. Curr Med Chem 2002; 9: 1737-49.

[109] Santa-Maria I, Hernández F, Del Rio J, Moreno FJ, Avila J. Tramiprosate, a drug of potential interest for the treatment of Alzheimer's disease, promotes an abnormal aggregation of tau. Mol Neurodegener 2007; 2 : 17

[110] Rosini M, Andrisano V, Bartolini M, et al. Rational approach to discover multipotent anti-Alzheimer drugs. J Med Chem 2005; 48: 360-3.

[111] Bilikiewicz A, Gaus W. Colostrinin (a naturally occurring, prolinerich, polypeptide mixture) in the treatment of Alzheimer's disease. J Alzheimers Dis 2004; 6: 17-26.

[112] Garcia-Alloza M, Borrelli LA, Rozkalne A, Hyman BT, Bacskai BJ. Curcumin labels amyloid pathology in vivo, disrupts existing plaques, and partially restores distorted neurites in an Alzheimer mouse model. J Neurochem 2007; 102: 1095-104.

[113] Baum L, Lam CW, Cheung SK, et al. Six-month randomized, placebo-controlled, double-blind, pilot clinical trial of curcumin in patients with Alzheimer disease. J Clin Psychopharmacol 2008; 28: 110-3.

[114] Smith DG, Cappai R, Barnham KJ. The redox chemistry of the Alzheimer's disease amyloid $\beta$ peptide. Biochim Biophys Acta 2007; 1768: 1976-90.

[115] Flinn JM, Hunter D, Linkous DH, et al. Enhanced zinc consumption causes memory deficits and increased brain levels of zinc. Physiol Behav 2005; 83: 793-803.

[116] Sampson E, Jenagaratnam L, McShane R. Metal protein attenuating compounds for the treatment of Alzheimer's disease. Cochrane Database Syst Rev 2008; (1): CD005380.

[117] Ferrer I, Boada Rovira M, Sánchez Guerra ML, Rey MJ, CostaJussá F. Neuropathology and pathogenesis of encephalitis following amyloid-beta immunization in Alzheimer's disease. Brain Pathol 2004; 14: 11-20.

[118] Gilman S, Koller M, Black RS, et al. Clinical effects of Abeta immunization (AN1792) in patients with AD in an interrupted trial. Neurology 2005; 64: 1553-62.

[119] Fox NC, Black RS, Gilman S, et al. Effects of Abeta immunization (AN1792) on MRI measures of cerebral volume in Alzheimer disease. Neurology 2005; 64: 1563-72.
[120] Pfeifer M, Boncristiano S, Bondolfi L, et al. Cerebral hemorrhage after passive anti-Abeta immunotherapy. Science 2002; 298: 1379.

[121] Rönnemaa E, Zethelius B, Sundelöf J, et al. Impaired insulin secretion increases the risk of Alzheimer disease. Neurology 2008; 71: 1065-71.

[122] Watson GS, Craft S. The role of insulin resistance in the pathogenesis of Alzheimer's disease: implications for treatment. CNS Drugs 2003; 17: 27-45.

[123] Risner ME, Saunders AM, Altman JF, et al. Rosiglitazone in Alzheimer's Disease Study Group. Efficacy of rosiglitazone in a genetically defined population with mild-to-moderate Alzheimer's disease. Pharmacogenomics J 2006; 6: 246-54.

[124] Watson GS, Cholerton BA, Reger MA, et al. Preserved cognition in patients with early Alzheimer disease and amnestic mild cognitive impairment during treatment with rosiglitazone: a preliminary study. Am J Geriatr Psychiatry 2005; 13: 950-8.

[125] Lago RM, Singh PP, Nesto RW. Congestive heart failure and cardiovascular death in patients with prediabetes and type 2 diabetes given thiazolidinediones: a meta-analysis of randomised clinical trials. Lancet 2007; 370: 1129-36.

[126] Reger MA, Watson GS, Green PS, et al. Intranasal insulin improves cognition and modulates beta-amyloid in early AD. Neurology 2008; 70: 440-8.

[127] Reger MA, Watson GS, Frey WH 2nd, et al. Effects of intranasal insulin on cognition in memory-impaired older adults: modulation by APOE genotype. Neurobiol Aging 2006; 27: 451-8.

[128] Higgins PJ. The TGF- $\beta 1 /$ upstream stimulatory factor-regulated PAI-1 gene: potential involvement and a therapeutic target in Alzheimer's disease. J Biomed Biotechnol 2006; 2006: 15792.

[129] Medina MG, Ledesma MD, Domínguez JE, et al. Tissue plasminogen activator mediates amyloid-induced neurotoxicity via Erk1/2 activation. EMBO J 2005; 24: 1706-16.

[130] Mouradian MM, Blin J, Giuffra M, et al. Somatostatin replacement therapy for Alzheimer dementia. Ann Neurol 1991; 30: 610-3.

[131] Burgos-Ramos E, Hervás-Aguilar A, Aguado-Llera D, et al. Somatostatin and Alzheimer's disease. Mol Cell Endocrinol 2008; 286: 104-11

[132] Saito T, Iwata N, Tsubuki S, et al. Somatostatin regulates brain amyloid beta peptide Abeta42 through modulation of proteolytic degradation. Nat Med 2005; 11: 434-9.

[133] Hooper C, Killick R, Lovestone S. The GSK3 hypothesis of Alzheimer's disease. J Neurochem 2008; 104: 1433-9.

[134] Tanimukai H, Grundke-Iqbal I, Iqbal K. Up-regulation of inhibitors of protein phosphatase-2A in Alzheimer's disease. Am J Pathol 2005; 166: 1761-71.

[135] Iqbal K, Grundke-Iqbal I. Alzheimer neurofibrillary degeneration: significance, etiopathogenesis, therapeutics and prevention. J Cell Mol Med 2008; 12: 38-55.

[136] Leclerc S, Garnier M, Hoessel R, et al. Indirubins inhibit glycogen synthase kinase-3 $\beta$ and CDK5/P25, two protein kinases involved in abnormal tau phosphorylation in Alzheimer's disease. J Biol Chem 2001; 276: 251-60

[137] Leost M, Schultz C, Link A, et al. Paullones are potent inhibitors of glycogen synthase kinase- $3 \beta$ and cyclin-dependent kinase 5/p25. Eur J Biochem 2000; 267: 5983-94.

[138] Mettey Y, Gompel M, Thomas V, et al. Aloisines, a new family of CDK/GSK-3 inhibitors. SAR study, crystal structure in complex with CDK2, enzyme selectivity, and cellular effects. J Med Chem 2003; 46: 222-36.

[139] Meijer L, Thunnissen A-MWH, White AW, et al. Inhibition of cyclin-dependent kinases, GSK-3 $\beta$ and CK1 by hymenialdisine, a marine sponge constituent. Chem Biol 2000; 7: 51-63.

[140] Engel T, Goñi-Oliver P, Gómez de Barreda E, Lucas JJ, Hernández F, Avila J. Lithium, a potential protective drug in Alzheimer's disease. Neurodegener Dis 2008; 5: 247-9.

[141] Ryves WJ, Dalton EC, Harwood AJ, Williams RSB. GSK-3 activity in neocortical cells is inhibited by lithium but not carbamazepine or valproic acid. Bipolar Disord 2005; 7: 260-5.

[142] Phiel CJ, Wilson CA, Lee VM, Klein PS. GSK-3alpha regulates production of Alzheimer's disease amyloid-beta peptides. Nature 2003; 423: 435-9.

[143] Feyt C, Kienlen-Campard P, Leroy K, et al. Lithium chloride increases the production of amyloid-beta peptide independently from its inhibition of glycogen synthase kinase 3. J Biol Chem 2005; 280: 33220-7. 
[144] Castro A, Encinas A, Gil C, et al. Non-ATP competitive glycogen synthase kinase 3beta (GSK-3beta) inhibitors: study of structural requirements for thiadiazolidinone derivatives. Bioorg Med Chem 2008; 16: 495-510.

[145] Luna-Medina R, Cortes-Canteli M, Sanchez-Galiano S, et al. NP031112, a thiadiazolidinone compound, prevents inflammation and neurodegeneration under excitotoxic conditions: potential therapeutic role in brain disorders. J Neurosci 2007; 27: 5766-76.

[146] Butler D, Bendiske J, Michaelis ML, Karanian DA, Bahr BA. Microtubule-stabilizing agent prevents protein accumulationinduced loss of synaptic markers. Eur J Pharmacol 2007; 562: 20-7.

[147] Asuni AA, Boutajangout A, Quartermain D, Sigurdsson EM. Immunotherapy targeting pathological tau conformers in a tangle mouse model reduces brain pathology with associated functional improvements. J Neurosci 2007; 27: 9115-29.

[148] Chappell AS, Gonzales C, Williams J, Witte MM, Mohs RC, Sperling R. AMPA potentiator treatment of cognitive deficits in Alzheimer disease. Neurology 2007; 68: 1008-12.

[149] Bachurin S, Bukatina E, Lermontova N, et al. Antihistamine agent Dimebon as a novel neuroprotector and a cognition enhancer. Ann NY Acad Sci 2001; 939: 425-35.

[150] Lermontova NN, Redkozubov AE, Shevtsova EF, Serkova TP, Kireeva EG, Bachurin SO. Dimebon and tacrine inhibit neurotoxic action of beta-amyloid in culture and block L-type $\mathrm{Ca}^{2+}$ channels. Bull Exp Biol Med 2001; 132: 1079-83.

[151] Bachurin SO, Shevtsova EP, Kireeva EG, Oxenkrug GF, Sablin SO. Mitochondria as a target for neurotoxins and neuroprotective agents. Ann NY Acad Sci 2003; 993: 334-44.

[152] Doody RS, Gavrilova SI, Sano M, et al. Effect of dimebon on cognition, activities of daily living, behavior, and global function in patients with mild-to-moderate Alzheimer's disease: a randomised, double-blind, placebo-controlled study. Lancet 2008; 372: 207-15.

[153] Pietá Dias C, Martins de Lima MN, Presti-Torres J, et al. Memantine reduces oxidative damage and enhances long-term recognition memory in aged rats. Neuroscience 2007; 146: 1719-25.

[154] Zoladz PR, Campbell AM, Park CR, Schaefer D, Danysz W, Diamond DM. Enhancement of long-term spatial memory in adult rats by the noncompetitive NMDA receptor antagonists, memantine and neramexane. Pharmacol Biochem Behav 2006; 85: 298-306.

[155] Zandi PP, Anthony JC, Khachaturian AS, et al. Reduced risk of Alzheimer disease in users of antioxidant vitamin supplements: the Cache County Study. Arch Neurol 2004; 61: 82-8.

[156] Grundman M. Vitamin E and Alzheimer disease: the basis for additional clinicals trials. Am J Clin Nutr 2000; 71: 630S-636S.

[157] Sano M, Ernesto C, Thomas RG, et al. A controlled trial of selegiline, alpha-tocopherol, or both as treatment for Alzheimer's disease. The Alzheimer's Disease Cooperative Study. N Engl J Med 1997; 336: 1216-22.

[158] Isaac M, Quinn R, Tabet N. Vitamin E for Alzheimer's disease and mild cognitive impairment. Cochrane Database Syst Rev 2000; (4): CD002854.

[159] Miller ER III, Pastor-Barriuso R, Dalal D, Riemersma RA, Appel LJ, Guallar E. Meta-analysis: high-dosage vitamin E supplementation may increase all-cause mortality. Ann Intern Med 2004; 142 : 37-46.

[160] DeKosky ST, Williamson JD, Fitzpatrick AL, et al. Ginkgo biloba for prevention of dementia: a randomized controlled trial. JAMA 2008; 300: 2253-62.

[161] McCarney R, Fisher P, Iliffe S, et al. Ginkgo biloba for mild to moderate dementia in a community setting: a pragmatic, randomised, parallel-group, double-blind, placebo-controlled trial. Int $\mathbf{J}$ Geriatr Psychiatry 2008; 23: 1222-30.

[162] Dodge HH, Zitzelberger T, Oken BS, Howieson D, Kaye J. A randomized placebo-controlled trial of ginkgo biloba for the prevention of cognitive decline. Neurology 2008; 70: 1809-17.

[163] Haemorrhage due to Ginkgo biloba? Prescrire Int 2008; 17: 19.

[164] Cheng Y, Feng Z, Zhang QZ, Zhang JT. Beneficial effects of melatonin in experimental models of Alzheimer disease. Acta Pharmacol Sin 2006; 27: 129-39.

[165] Wang JZ, Wang ZF. Role of melatonin in Alzheimer-like neurodegeneration. Acta Pharmacol Sin 2006; 27: 41-9.

[166] Brunner P, Sözer-Topcular N, Jockers R, et al. Pineal and cortical melatonin receptors MT1 and MT2 are decreased in Alzheimer's disease. Eur J Histochem 2006; 50: 311-6.

[167] Rodríguez-Franco MI, Fernández-Bachiller MI, Pérez C, Hernández-Ledesma B, Bartolomé B. Novel tacrine-melatonin hy- brids as dual-acting drugs for Alzheimer disease, with improved acetylcholinesterase inhibitory and antioxidant properties. J Med Chem 2006; 49: 459-62.

[168] Birks J, Flicker L. Selegiline for Alzheimer's disease. Cochrane Database Syst Rev 2003; (1): CD000442.

[169] Youdim MB, Bar Am O, Yogev-Falach M, et al. Rasagiline: neurodegeneration, neuroprotection, and mitochondrial permeability transition. J Neurosci Res 2005; 79: 172-9.

[170] Youdim MB, Amit T, Bar-Am O, Weinreb O, Yogev-Falach M. Implications of co-morbidity for etiology and treatment of neurodegenerative diseases with multifunctional neuroprotectiveneurorescue drugs; ladostigil. Neurotox Res 2006; 10: 181-92.

[171] De Bruin VM, Vieira MC, Rocha MN, Viana GS. Cortisol and dehydroepiandrosterone sulfate plasma levels and their relationship to aging, cognitive function, and dementia. Brain Cogn 2002; 50: 316-23.

[172] Brown ES, Woolston D, Frol A, et al. Hippocampal volume, spectroscopy, cognition, and mood in patients receiving corticosteroid therapy. Biol Psychiatry 2004; 55: 538-45.

[173] Bastianetto S, Ramassamy C, Poirier J, Quirion R. Dehydroepiandrosterone (DHEA) protects hippocampal cells from oxidative stress-induced damage. Brain Res Mol Brain Res 1999; 66: 35-41.

[174] Kimonides VG, Khatibi NH, Svendsen CN, Sofroniew MV, Herbert J. Dehydroepiandrosterone (DHEA) and DHEA-sulfate (DHEAS) protect hippocampal neurons against excitatory amino acid-induced neurotoxicity. Proc Natl Acad Sci USA 1998; 95: 1852-7.

[175] Wolkowitz OM, Kramer JH, Reus VI, et al, and the DHEAAlzheimer's Disease Collaborative Research Group. DHEA treatment of Alzheimer's disease: a randomized, double-blind, placebocontrolled study. Neurology 2003; 60: 1071-6.

[176] Wang R, Yan H, Tang XC. Progress in studies of huperzine A, a natural cholinesterase inhibitor from Chinese herbal medicine. Acta Pharmacol Sin 2006; 27: 1-26.

[177] Fu H, Li W, Luo J, et al. Promising anti-Alzheimer's dimer bis(7)tacrine reduces beta-amyloid generation by directly inhibiting BACE-1 activity. Biochem Biophys Res Commun 2008; 366: 6316.

[178] Ma QL, Teter B, Ubeda OJ, et al. Omega-3 fatty acid docosahexaenoic acid increases SorLA/LR11, a sorting protein with reduced expression in sporadic Alzheimer's disease (AD): relevance to AD prevention. J Neurosci 2007; 27: 14299-307.

[179] Farooqui AA, Ong WY, Horrocks LA, Chen P, Farooqui T. Comparison of biochemical effects of statins and fish oil in brain: the battle of the titans. Brain Res Rev 2007; 56: 443-71.

[180] Lim GP, Calon F, Morihara T, et al. A diet enriched with the omega-3 fatty acid docosahexaenoic acid reduces amyloid burden in an aged Alzheimer mouse model. J Neurosci 2005; 25: 3032-40.

[181] Calon F, Lim GP, Yang F, et al. Docosahexaenoic acid protects from dendritic pathology in an Alzheimer's disease mouse model. Neuron 2004; 43: 633-45.

[182] Green KN, Martinez-Coria H, Khashwji H, et al. Dietary docosahexaenoic acid and docosapentaenoic acid ameliorate amyloid- $\beta$ and tau pathology via a mechanism involving presenilin 1 levels. J Neurosci 2007; 27: 4385-95.

[183] Whalley LJ, Deary IJ, Starr JM, et al. n-3 Fatty acid erythrocyte membrane content, $A P O E \varepsilon 4$, and cognitive variation: an observational follow-up study in late adulthood. Am J Clin Nutr 2008; 87: 449-54.

[184] Barberger-Gateau P, Raffaitin C, Letenneur L, et al. Dietary patterns and risk of dementia: the Three-City cohort study. Neurology 2007; 69: 1921-30.

[185] Freund-Levi Y, Eriksdotter-Jönhagen M, Cederholm T, et al. Omega-3 fatty acid treatment in 174 patients with mild to moderate Alzheimer disease: OmegAD study: a randomized double-blind trial. Arch Neurol 2006; 63: 1402-8.

[186] Chauhan NB, Siegel GJ, Feinstein DL. Propentofylline attenuates tau hyperphosphorylation in Alzheimer's Swedish mutant model Tg2576. Neuropharmacology 2005; 48: 93-104.

[187] Rother M, Erkinjuntti T, Roessner M, Kittner B, Marcusson J, Karlsson I. Propentofylline in the treatment of Alzheimer's disease and vascular dementia: a review of phase III trials. Dement Geriatr Cogn Disord 1998; 9 (suppl 1): 36-43.

[188] Frampton M, Harvey RJ, Kirchner V. Propentofylline for dementia. Cochrane Database Syst Rev 2003; (2): CD002853. 
[189] Mielke R, Ghaemi M, Kessler J, et al. Propentofylline enhances cerebral metabolic response to auditory memory stimulation in Alzheimer's disease. J Neurol Sci 1998; 154: 76-82.

[190] Yamasaki TR, Blurton-Jones M, Morrissette DA, Kiatzawa M, Oddo S, LaFerla FM. Neural stem cells improve memory in an inducible mouse model of neuronal loss. J Neurosci 2007; 27: 1192533 .

[191] Sugaya K, Alvarez A, Marutle A, Kwak YD, Choumkina E. Stem cell strategies for Alzheimer's disease therapy. Panminerva Med 2006; 48: 87-96.

[192] Wang Q, Matsumoto Y, Shindo T, et al. Neural stem cells transplantation in cortex in a mouse model of Alzheimer's disease. $\mathrm{J}$ Med Invest 2006; 53: 61-9.

[193] Lovell MA, Geiger H, Van Zant GE, Lynn BC, Markesbery WR. Isolation of neural precursor cells from Alzheimer's disease and aged control postmortem brain. Neurobiol Aging 2006; 27: 909-17.

[194] Tsai KJ, Tsai YC, Shen CKJ. G-CSF rescues the memory impairment of animal models of Alzheimer's disease. J Exp Med 2007; 204: 1273-80

[195] Zhan YQ, Wang FR, Li FG, Xing BZ, Fang X, Zhang SM. Study on distribution of neural stem cells in the brain of Alzheimer disease transgenic mice through caudal vein transplantation. Zhonghua Yi Xue Za Zhi 2007; 87: 1786-8 (article in Chinese, abstract in PUBMED)

[196] Sugaya K, Kwak YD, Ohmitsu O, Marutle A, Greig NH, Choumrina E. Practical issues in stem cell therapy for Alzheimer's disease. Curr Alzheimer Res 2007; 4: 370-7.

[197] Marutle A, Ohmitsu M, Nilbratt M, Greig NH, Nordberg A, Sugaya K. Modulation of human neural stem cell differentiation in Alzheimer (APP23) transgenic mice by phenserine. Proc Natl Acad Sci USA 2007; 104: 12506-11.

[198] Tuszynski MH, Thal L, Pay M, et al. A phase 1 clinical trial of nerve growth factor gene therapy for Alzheimer disease. Nat Med 2005; 11: 551-5.

[199] Davies P, Maloney AJ. Selective loss of central cholinergic neurons in Alzheimer's disease. Lancet 1976; 2: 1403.

[200] Peters BH, Levin HS. Effects of physostigmine and lecithin on memory in Alzheimer disease. Ann Neurol 1979; 6: 219-21.

[201] Muramoto O, Sugishita M, Sugita H, Toyokura Y. Effect of physostigmine on constructional and memory tasks in Alzheimer's disease. Arch Neurol 1979; 36: 501-3.

[202] Summers WK, Viesselman JO, Marsh GM, Candelora K. Use of THA in treatment of Alzheimer-like dementia: pilot study in twelve patients. Biol Psychiatry 1981; 16: 145-53.
[203] Tagawa K, Kunishita T, Maruyama K, et al. Alzheimer's disease amyloid beta-clipping enzyme (APP secretase): identification, purification, and characterization of the enzyme. Biochem Biophys Res Commun 1991; 177: 377-87.

[204] Wolfe MS, De Los Angeles J, Miller DD, Xia W, Selkoe DJ. Are presenilins intramembrane-cleaving proteases? Implications for the molecular mechanism of Alzheimer's disease. Biochemistry 1999; 38: 11223-30.

[205] Vassar R, Bennett BD, Babu-Khan S, et al. $\beta$-Secretase cleavage of Alzheimer's amyloid precursor protein by the transmembrane aspartic protease BACE. Science 1999; 286: 735-41.

[206] Braak H, Braak E. Evolution of neuronal changes in the course of Alzheimer's disease. J Neural Transm Suppl 1998; 53: 127-40.

[207] Parsons CG, Stöffler A, Danysz W. Memantine: a NMDA receptor antagonist that improves memory by restoration of homeostasis in the glutamatergic system. Too little activation is bad, too much is even worse. Neuropharmacology 2007; 53: 699-723.

[208] Harold D, Macgregor S, Patterson CE, et al. A single nucleotide polymorphism in CHAT influences response to acetylcholinesterase inhibitors in Alzheimer's disease. Pharmacogenet Genomics 2006; 16: 75-7.

[209] Simon T, Becquemont L, Mary-Krause M, et al. Combined glutathione-S-transferase $\mathrm{M} 1$ and $\mathrm{T} 1$ genetic polymorphism and tacrine hepatotoxicity. Clin Pharmacol Ther 2000; 67: 432-7.

[210] Varsaldi F, Miglio G, Scordo MG, et al. Impact of the CYP2D6 polymorphism on steady-state plasma concentrations and clinical outcome of donepezil in Alzheimer's disease patients. Eur J Clin Pharmacol 2006; 62: 721-6.

[211] Blesa R, Bullock R, He Y, et al. Effect of butyrylcholinesterase genotype on the response to rivastigmine or donepezil in younger patients with Alzheimer's disease. Pharmacogenet Genomics 2006; 16: 771-4.

[212] Vasto S, Candore G, Duro G, Lio D, Grimaldi MP, Caruso C. Alzheimer's disease and genetics of inflammation: a pharmacogenomic vision. Pharmacogenomics 2007; 8: 1735-45.

[213] Weggen S, Eriksen JL, Sagi SA, et al. Evidence that nonsteroidal anti-inflammatory drugs decrease amyloid beta 42 production by direct modulation of gamma-secretase activity. J Biol Chem 2003 278: 31831-7.

[214] Czirr E, Leuchtenberger S, Dorner-Ciossek C, et al. Insensitivity to Abeta42-lowering nonsteroidal antiinflammatory drugs and gamma-secretase inhibitors is common among aggressive presenilin-1 mutations. J Biol Chem 2007; 282: 24504-13.

(C) Alfredo Robles; Licensee Bentham Open.

This is an open access article licensed under the terms of the Creative Commons Attribution Non-Commercial License (http://creativecommons.org/licenses/by-nc/3.0/) which permits unrestricted, non-commercial use, distribution and reproduction in any medium, provided the work is properly cited. 